University of Wollongong

Research Online

Australian Institute for Innovative Materials -

Papers

Australian Institute for Innovative Materials

$1-1-2017$

\title{
Effects of Fluorine and Chromium Doping on the Performance of Lithium- Rich Li1+xMO2(M = Ni, Mn, Co) Positive Electrodes
}

\author{
Wei Kong Pang \\ University of Wollongong, wkpang@uow.edu.au \\ Hsiu-Fen Lin \\ National Formosa University \\ Vanessa K. Peterson \\ University of Wollongong, vep@ansto.gov.au \\ Cheng-Zhang Lu \\ Industrial Technology Research Institute, Taiwan \\ Chia-Erh Liu \\ Industrial Technology Research Institute, Taiwan
}

See next page for additional authors

Follow this and additional works at: https://ro.uow.edu.au/aiimpapers

Part of the Engineering Commons, and the Physical Sciences and Mathematics Commons

\footnotetext{
Research Online is the open access institutional repository for the University of Wollongong. For further information
} contact the UOW Library: research-pubs@uow.edu.au 


\title{
Effects of Fluorine and Chromium Doping on the Performance of Lithium-Rich Li1+xMO2(M = Ni, Mn, Co) Positive Electrodes
}

\begin{abstract}
Lithium-rich metal oxides $\mathrm{Li} 1+\mathrm{z} \mathrm{MO} 2(\mathrm{M}=\mathrm{Ni}$, Co $\mathrm{Mn}$, etc) are promising positive electrode materials for high-energy lithium-ion batteries, with capacities of 250-300 mAh.g -1 that closely approach theoretical intercalation limits. Unfortunately, these materials suffer severe capacity fade on cycling, amongst other performance issues. Whilst ion substitution can improve the performance of many of these materials, the underlying mechanisms of property modification are not completely understood. In this work we show enhanced performance of the $\mathrm{Li} 1+\mathrm{Z} \mathrm{MO} 2$ electrode, consisting of $\mathrm{Li} 2 \mathrm{MnO} 3$ (with $\mathrm{C} 2 / \mathrm{m}$ space group) and LiMO 2 (with R3m space group) phases, and establish the effects of cationic and anionic substitution on the phase and structure evolution underpinning performance changes. Whist the undoped material has a high capacity of $\sim 270$ mAh.g -1 , only $79 \%$ of this remains after 200 cycles. Including $\sim 2 \% \mathrm{Cr}$ in the material, likely at the R3m metal (3a) site, improved cycle performance by 13\% and including $\sim 5 \% \mathrm{~F}$ in the material, likely at the R3m oxygen (6c) site, enhanced capacity by 4-5\% at the expense of a 12\% decline in cycle performance. Moreover, $\mathrm{Cr}$ doping enhances energy density retention by $\sim 13 \%$ and $\mathrm{F}$ doping suppresses this by $17 \%$. We find that these changes arise by different mechanisms. Both anionic and cationic substitution promote faster Li diffusion, by $48 \%$ and $20 \%$, respectively, as determined using cyclic voltammetry and leading to better rate performance. Unlike anionic substitution, cationic substitution enhances structural stability at the expense of some capacity, by suppressing lattice distortion during Li insertion and extraction. This work implicates strategic cationic-anionic co-doping for enhanced electrochemical performance in lithium-rich layered metal-oxide phases.

\section{Disciplines}

Engineering | Physical Sciences and Mathematics

\section{Publication Details}

Pang, W., Lin, H., Peterson, V. K., Lu, C., Liu, C., Liao, S. \& Chen, J. (2017). Effects of Fluorine and Chromium Doping on the Performance of Lithium-Rich Li1+xMO2(M = Ni, Mn, Co) Positive Electrodes. Chemistry of Materials, 29 (24), 10299-10311.

\section{Authors}

Wei Kong Pang, Hsiu-Fen Lin, Vanessa K. Peterson, Cheng-Zhang Lu, Chia-Erh Liu, Shih-Chieh Liao, and Jin Chen
\end{abstract}




\title{
Effects of Fluorine and Chromium Doping on the Performance of Lithium-Rich $\mathrm{Li}_{1+\mathrm{x}} \mathrm{MO}_{2}(\mathrm{M}=\mathrm{Ni}, \mathrm{Mn}, \mathrm{Co})$ Positive Electrodes
}

\author{
Wei Kong Pang, ${ }^{1,2}$ Hsiu-Fen Lin, ${ }^{3}$ Vanessa K. Peterson, ${ }^{1,2 *}$ Cheng-Zhang Lu, ${ }^{4}$ Chia-Erh Liu, ${ }^{4}$ Shih-Chieh \\ Liao, ${ }^{4}$ Jin-Ming Chen ${ }^{4}$ \\ ${ }^{1}$ Australian Centre for Neutron Scattering, Australian Nuclear Science and Technology Organization, Locked Bag 2001, \\ Kirrawee DC, NSW 2232, Australia. \\ ${ }^{2}$ Institute for Superconducting \& Electronic Materials, Faculty of Engineering, University of Wollongong, NSW 2522, Aus- \\ tralia. \\ ${ }^{3}$ Department of Materials Science and Engineering, National Formosa University, Yunlin County 63201, Taiwan. \\ ${ }^{4}$ Department of Energy Nanomaterials, Material \& Chemical Research Laboratory, Industrial Technology Research Institute, \\ Taiwan. \\ *Corresponding author
}

KEYWORDS: lithium-ion battery; in operando; neutron powder diffraction; lithium-rich; cathode.

\begin{abstract}
Lithium-rich metal oxides $\mathrm{Li}_{1+z} M \mathrm{O}_{2}(M=\mathrm{Ni}$, Co Mn, etc) are promising positive electrode materials for high-energy lithium-ion batteries, with capacities of 250-300 mAh.g ${ }^{-1}$ that closely approach theoretical intercalation limits. Unfortunately, these materials suffer severe capacity fade on cycling, amongst other performance issues. Whilst ion substitution can improve the performance of many of these materials, the underlying mechanisms of property modification are not completely understood. In this work we show enhanced performance of the $\mathrm{Li}\left(\mathrm{Li}_{0.13} \mathrm{Ni}_{0.24} \mathrm{Co}_{0.12} \mathrm{Mn}_{0.5}\right) \mathrm{O}_{2}$ electrode, consisting of $\mathrm{Li}_{2} \mathrm{MnO}_{3}$ (with $C 2 / m$ space group) and $\mathrm{Li}_{M} \mathrm{O}_{2}$ (with $R \overline{3} m$ space group) phases, and establish the effects of cationic and anionic substitution on the phase and structure evolution underpinning performance changes. Whist the undoped material has a high capacity of $\sim 270 \mathrm{mAh} \cdot \mathrm{g}^{-1}$, only $79 \%$ of this remains after 200 cycles. Including $\sim 2 \% \mathrm{Cr}$ in the material, believed to reside at the $R \overline{3} m$ metal $(3 a)$ site, improved cycle performance by $\sim 13 \%$ and including $\sim 5 \% \mathrm{~F}$ in the material, believed to reside at the $R \overline{3} m$ oxygen (6c) site, enhanced capacity by $\sim 4-5 \%$ at the expense of $\mathrm{a} \sim 12 \%$ decline in cycle performance. Moreover, $\mathrm{Cr}$ doping enhances energy density retention by $\sim 13 \%$ and $\mathrm{F}$ doping suppresses this by $17 \%$. We find that these changes arise by different mechanisms. Both anionic and cationic substitution promote faster Li diffusion, by $48 \%$ and $20 \%$, respectively, as determined using cyclic voltammetry and leading to better rate performance. Unlike anionic substitution, cationic substitution enhances structural stability at the expense of some capacity, by suppressing lattice distortion during $\mathrm{Li}$ insertion and extraction. This work implicates strategic cationic-anionic co-doping for enhanced electrochemical performance in lithium-rich layered metal-oxide phases.
\end{abstract}

\section{- INTRODUCTION}

Lithium-ion batteries (LIBs) are the most promising energy-storage technology for electric and plug-in hybridelectric vehicle applications, however, the energy density of existing LIB technology needs to improve to meet emerging market requirements. ${ }^{1-3}$ The major bottleneck for this improvement is the positive electrode, with the first commercialized and commonly used LIB positive electrode material, $\mathrm{LiCoO}_{2}$, now superseded by stoichiometric $\mathrm{LiNi}_{\mathrm{x}} \mathrm{Co}_{1-\mathrm{x}-\mathrm{y}} \mathrm{Mn}_{\mathrm{y}} \mathrm{O}_{2}$ (such as $\left.\mathrm{LiNi}_{1 / 3} \mathrm{Co}_{1 / 3} \mathrm{Mn}_{1 / 3} \mathrm{O}_{2}\right)^{4,5}$ and its Li-rich siblings $\mathrm{Li}_{1+z} \mathrm{Ni}_{\mathrm{x}} \mathrm{Co}_{1-\mathrm{x}-\mathrm{y}-\mathrm{z}} \mathrm{Mn}_{\mathrm{y}} \mathrm{O}_{2}$ (commonly appearing as the composite $x \mathrm{Li}_{2} \mathrm{MnO}_{3} .(1-x) \mathrm{Li} M \mathrm{O}_{2}$, with $M=\mathrm{Ni}, \mathrm{Co}$, $\mathrm{Mn})^{6-10}$. These are a technologically-important class of positive-electrodes, offering the possibility for higher energy density at reduced cost. In particular, the $\mathrm{Li}_{1+x} M \mathrm{O}_{2}$ or
$\mathrm{xLi}_{2} \mathrm{MnO}_{3} \cdot(1-\mathrm{x}) \mathrm{Li} M \mathrm{O}_{2}$ (where $M$ are transition metals) material has been reported with various phases, including as a single $\mathrm{Li}_{1+x} \mathrm{MO}_{2}$ phase and as a two-phase system with a main $\mathrm{Li} M \mathrm{O}_{2}$ phase containing nanodomains of $\mathrm{Li}_{2} \mathrm{MnO}_{3}$. $^{6-10}$ The single-phase $\mathrm{Li}_{1+x} M \mathrm{O}_{2}$ is reported with $R \overline{3} m$ space group symmetry and stacking faults in the lithium/manganese layers along the $c$-axis. ${ }^{6}$ The main phase of the two-phase system has $R \overline{3} \mathrm{~m}$ space group symmetry that contains an intergrowth of a monoclinic $\mathrm{Li}_{2} \mathrm{MnO}_{3}$-like phase with $C 2 / m$ space group symmetry, with these phases hetero-interface in particle grains. ${ }^{8}$ Notably, diffraction data of the material contain reflections that are unindexed by the $R \overline{3} m$ space group, and it is these reflections that are the source of phase composition discrepancies. Importantly, neutron powder diffraction (NPD) is particularly sensitive to this material structure, where the coherent neutron 
scattering lengths for the elements commonly found in this material, $\mathrm{Li}, \mathrm{Cr}, \mathrm{Ni}, \mathrm{Mn}$, and $\mathrm{Co}$, are $-1.9,3.6,10.3,-3.7$, and $2.5 \times 10^{-15} \mathrm{~m}$, respectively. Consequently, work characterizing the $\mathrm{Li}_{1+\mathrm{x}} M \mathrm{O}_{2}$ material using high resolution NPD confirm a two-phase composition with a main layered $R \overline{3} \mathrm{~m}$ $\mathrm{Li} M \mathrm{O}_{2}$ phase and $C 2 / m \mathrm{Li}_{2} \mathrm{MnO}_{3}$ second phase. ${ }^{11}$ However, the use of NPD to study $\mathrm{Li}_{1+\mathrm{x}} M \mathrm{O}_{2}$ is relatively rare, perhaps as a result of difficulties accessing the limited neutron facilities.

Despite their structural complexity, $\mathrm{Li}_{1+x} M \mathrm{O}_{2}$ materials are attracting increasing attention as LIB positive electrodes due to their low cost/toxicity and high capacity of $\sim 250-$ 280 mAh.g ${ }^{-1}, 12-14$ and because they suffer from severe voltage decay issues thought to originate from a $3 \mathrm{~V}$ transformation to a spinel-like phase. ${ }^{15-17}$ Cation mixing caused by the similar ionic radii of $\mathrm{Ni}^{2+}$ and $\mathrm{Li}^{+}$possibly also leads to unsatisfactory rate and cycle performance at high currents. The mechanism of capacity fade in $\mathrm{Li}_{1+x} M \mathrm{O}_{2}$ has been studied by several researchers. ${ }^{14-18}$ Using the combination of in operando NPD and synchrotron transmission X-ray microscopy, particle cracking in combination with grain boundary movement was revealed to underpin capacity fade. ${ }^{11}$ Similarly, Song et al. report that phase-separation is responsible for the gradual reduction in discharge voltage ${ }^{16}$ It is also reported that cycle deterioration can be suppressed by pre-cycling treatment during which the upper potential limit of $4.5 \mathrm{~V}$ is increased by $0.1 \mathrm{~V}$ every two cycles to $4.8 \mathrm{~V}$ during initial cycling. ${ }^{19}$ The pretreatment at the lower voltage range was shown to reduce structural changes and surface micro-cracking, improving cycle stability. ${ }^{19}$

The electrochemical performance of $\mathrm{LiNi}_{\mathrm{x}} \mathrm{Co}_{1-\mathrm{x}-\mathrm{y}} \mathrm{Mn}_{\mathrm{y}} \mathrm{O}_{2}$ can also be enhanced by structure modification via doping with foreign elements such as alkaline earth metals, ${ }^{20-22}$ transition metals, ${ }^{23-26}$ rare earth metals, ${ }^{27,28}$ and halogen elements. ${ }^{29-32}$ Despite the complicated Ni:Co:Mn doping in $\mathrm{LiNi}_{\mathrm{x}} \mathrm{Co}_{1-\mathrm{x}-\mathrm{y}} \mathrm{Mn}_{\mathrm{y}} \mathrm{O}_{2}$ or $\mathrm{Li}_{1+\mathrm{z}} \mathrm{Ni}_{\mathrm{x}} \mathrm{Co}_{1-\mathrm{x}-\mathrm{y}-\mathrm{z}} \mathrm{Mn}_{\mathrm{y}} \mathrm{O}_{2}$, cationic substitution for $\mathrm{Ni}^{2+}$ can stabilize the structure and reduce $\mathrm{Li} / \mathrm{Ni}$ mixing, thereby modifying electrochemical performance. ${ }^{20-}$ ${ }^{28}$ Where a relatively-large radius dopant is incorporated, an increase in the material's $c$ lattice parameter has been observed and correlated with decreased transfer resistance. ${ }^{28}$ Anionic substitution with halogens such as $\mathrm{F}$ for 0 has also been useful in altering grain size and improving crystallinity, as well as stabilizing the electrode/electrolyte interface and thereby improving cycle performance. ${ }^{29-32}$ The resulting electronic modification is also reported to hinder the loss of 0 through the relatively-stronger F-metal bond in Li-rich compounds. ${ }^{32}$ Whilst these doping strategies can be effective in modifying electrochemical behavior, the potential existence of nanodomains of $\mathrm{Li}_{2} \mathrm{MnO}_{3}$ and $\mathrm{Li} M \mathrm{O}_{2}$ components $^{8-10}$ as well as complex doping in singlephase $\mathrm{Li}_{1+x} \mathrm{MO}_{2},{ }^{7}$ leads to difficulties in establishing the link between doping and electrochemical performance.

In this work, we use NPD to study the phase and structure of pristine, Cr-doped, and F-doped $\mathrm{Li}\left(\mathrm{Li}_{0.13} \mathrm{Ni}_{0.24} \mathrm{Co}_{0.12} \mathrm{Mn}_{0.5}\right) \mathrm{O}_{2}$ positive lithium-ion battery electrodes and their evolution during battery cycling and establish their structure-function relationship.

\section{- EXPERIMENTAL}

A study of $\mathrm{Li}\left(\mathrm{Li}_{0.13} \mathrm{Ni}_{0.24} \mathrm{Co}_{0.12} \mathrm{Mn}_{0.5}\right) \mathrm{O}_{2}$ with $2 \% \mathrm{Cr}$ and $5 \% \mathrm{~F}$ was chosen on the basis of preliminary performance tests at $1 \mathrm{C}$. Tests of 1,2 , and $3 \% \mathrm{Cr}$ revealed that $2 \% \mathrm{Cr}$ induced the smallest first cycle irreversibility. Tests of $5,7.5$, and $10 \% \mathrm{~F}$ revealed $5 \% \mathrm{~F}$ to yield the highest capacity and best rate capability (see Figure S1).

Pristine, Cr-doped, and F-doped $\mathrm{Li}\left(\mathrm{Li}_{0.13} \mathrm{Ni}_{0.24} \mathrm{Co}_{0.12} \mathrm{Mn}_{0.5}\right) \mathrm{O}_{2}$ are termed LNCM, Cr-LNCM, and F-LNCM, respectively. LNCM, Cr-LNCM, and F-LNCM powders were synthesized via a carbonate co-precipitation process. Stoichiometric amounts of manganese sulfate $\left(\mathrm{MnSO}_{4} \bullet \mathrm{H}_{2} \mathrm{O}\right)$, nickel sulfate $\left(\mathrm{NiSO}_{4} \bullet 7 \mathrm{H}_{2} \mathrm{O}\right)$, and cobalt sulfate $\left(\mathrm{CoSO}_{4} \bullet 7 \mathrm{H}_{2} \mathrm{O}\right)$ were dissolved in deionized water and used as the starting materials. The starting materials were added dropwise into a continuously-stirred reactor tank, into which $\mathrm{Na}_{2} \mathrm{CO}_{3}$ as precipitator and $\mathrm{NH}_{4} \mathrm{OH}$ as chelating agent were separately fed. The solutions were maintained at $60^{\circ} \mathrm{C}$, a pH of $7.5-$ 8.5, and at $800 \mathrm{rpm}$ stirring. After formation, the spherical carbonate precursor powders were filtered, washed, and dried at $120{ }^{\circ} \mathrm{C}$. The carbonate precursors were then mixed with the required amount of lithium hydroxide $(\mathrm{LiOH})$ and calcined at $900{ }^{\circ} \mathrm{C}$ in air for $16 \mathrm{~h}$ to form black powder LNCM. Fluorine and chromium were doped into the LNCM powders by mixing and calcining with appropriate amounts of $\mathrm{NH}_{4} \mathrm{~F}$ and $\mathrm{Cr}\left(\mathrm{NO}_{3}\right)_{3} \bullet \mathrm{H}_{2} \mathrm{O}$, respectively. The mixtures were thoroughly ground and calcined at $600{ }^{\circ} \mathrm{C}$ for 4 $\mathrm{h}$ in air to produce F-LNCM and Cr-LNCM. A lower temperature $\left(600^{\circ} \mathrm{C}\right)$ was used in the post annealing to maintain parental LNCM form.

$\mathrm{X}$-ray powder diffraction (XRPD) data over the $2 \theta$ range 10 - 80 ${ }^{\circ}$ with a step size of $0.02^{\circ}$ were collected for asprepared LNCM, Cr-LNCM, and F-LNCM powders using an $\mathrm{X}$ 'pert Pro with $\mathrm{CuK} \alpha$ radiation. High-resolution neutron powder diffraction (NPD) data of LNCM, Cr-LNCM, and FLNCM were obtained using ECHIDNA, the high-resolution neutron powder diffractometer with 1.6211(5) Å neutrons (determined using the $\mathrm{La}^{11} \mathrm{~B}_{6}$ NIST standard reference material 660b) at the Open Pool Australian Light-water (OPAL) research reactor at the Australian Nuclear Science and Technology Organisation (ANSTO). ${ }^{33}$ NPD data were obtained over the $2 \theta$ range $6.5-164^{\circ}$ with a step size of $0.05^{\circ}$. GSAS-II ${ }^{34}$ was employed to perform Rietveld analysis of the high-resolution NPD data, where the refined parameters included background coefficients, the zero-shift, peak shape parameters, lattice parameters, atomic positional parameters, atomic displacement parameters $\left(U_{\text {iso }}\right)$, and site occupancy factors. The data were described successfully by a two-phase model using a main hexagonal $R \overline{3} \mathrm{~m}$ phase $^{10,28}$ and a secondary monoclinic $C 2 / m$ phase. ${ }^{6,9}$ In the refinement the atomic concentrations of atoms were initially set to the target values and the total occupancy of each site constrained to unity. The zero shift in the final refinements varied between $-0.06(1)$ to $-0.08(2)$.

The morphology of the as-synthesized samples was examined using field-emission scanning electron microscopy (FE-SEM) with a Hitachi SU8000 operated at $15 \mathrm{keV}$. Elemental weight fractions were determined using inductively coupled plasma atomic emission spectrometry (ICP-AES, 
S-35, Kontron). To perform ICP-AES measurements, the samples were digested in Aqua Regia $\left(\mathrm{HNO}_{3}+3 \mathrm{HCl}\right)$ and further diluted with deionized water.

LNCM, Cr-LNCM, and F-LNCM powders were used as active materials in coin cells by mixing with conductive carbon (Super P) and polyvinylidene difluoride (PVDF) binder in a weight ratio of $80: 10: 10$ in an adequate amount of $\mathrm{N}$ methyl-2-pyrrolidone (NMP). The mixed slurry was coated onto aluminum foil and dried at $80{ }^{\circ} \mathrm{C}$ for $1 \mathrm{~h}$ to evaporate the organic solvent. The coated foil was roll-pressed and dried at $100{ }^{\circ} \mathrm{C}$ for $12 \mathrm{~h}$ in a vacuum furnace to obtain the electrode. The electrodes were assembled into CR2032type coin cells with Li metal as the counter electrode and 1 $\mathrm{M} \mathrm{LiPF}_{6}$ dissolved in a 1:1 mixture by volume of ethylene carbonate (EC) and dimethyl carbonate (DMC) as the electrolyte for electrochemical characterizations. Coin cells were assembled in a glove box under an argon atmosphere. Cyclic voltammetry (CV) curves were recorded at scan rates of $0.1,0.2,0.4,0.8$, and $1 \mathrm{mV} . \mathrm{s}^{-1}$ within the range 2.0 - $5.0 \mathrm{~V}$ (vs. Li) using an Autolab potentiostat/galvanostat (PG302N). The CVs of the batteries at $2^{\text {nd }}$ cycle were used to calculate the lithium diffusivity. Further electrochemical testing within the voltage window 2.0 $4.8 \mathrm{~V}$ (vs. Li) was performed using a Maccor series 4000 (USA). Cycle performance tests were also conducted using full-configuration coin cells with $\mathrm{Li}_{4} \mathrm{Ti}_{5} \mathrm{O}_{12}$ (LTO) as the counter electrode in the voltage window $0.5-3.3 \mathrm{~V}$ (vs. LTO). The specific capacity of the cells was calculated based on the weight of active positive electrodes (LNCM, Cr-LNCM, and F-LNCM).

In operando NPD measurements were performed using standard 18650-type full batteries. The 18650 full batteries with Celgard ${ }^{\circledR}$ separator were prepared by the Industrial Technology Research Institute (ITRI) of Taiwan. LNCM and LTO electrodes for these full-batteries were prepared by casting a slurry of active material (80 wt.\%), acetylene black (10 wt.\%), and PVDF binder (10 wt.\%), dissolved in NMP onto Al foil using a double-sided coating machine. The single sided coating thickness of LNCM and LTO was 62 and $139 \mu \mathrm{m}$, respectively, resulting in a LNCM : LTO loading of 1: 1.13 (mAh) with LNCM being the limiting material. Electrode dimensions of $85 \times 5.5 \mathrm{~cm}^{2}$ were rolled with 2 layers of separator, and each battery contained $\sim 5$ g electrolyte. In operando NPD data of the 18650-type batteries were collected using WOMBAT, 35 the high-intensity neutron powder diffractometer at the OPAL research reactor at ANSTO. The 18650-type batteries are an ideal geometry for the WOMBAT diffractometer and were galvanostatically charged and discharged at $0.1 \mathrm{~A}$ between 0.5 and $3.3 \mathrm{~V}$ (Vs. LTO). The charge-discharge process was performed using an Autolab potentiostat/galvanostat (PG302N) under ambient conditions, with the external temperature maintained at $22.5{ }^{\circ} \mathrm{C}$. A neutron beam with a wavelength of 2.4123(2) Å was used, determined using the $\mathrm{La}^{11} \mathrm{~B}_{6}$ NIST Standard Reference Material $660 \mathrm{~b}$. The diffractograms were obtained with an exposure time of $1 \mathrm{~min}$ per pattern in the angular range 16.1 - $136.9^{\circ}$ during charge-discharge cycling. Single-peak fitting of the LNCM 012 and LTO 222 reflections was performed using the Large Array Manipulation Program. ${ }^{36}$

\section{- RESULTS AND DISCUSSION}

The molar fraction of elements obtained from ICP-AES for the as-synthesized LNCM, Cr-LNCM, and F-LNCM materials are shown in Table 1. Scanning electron microscopy (SEM, Figure S2) shows that the doping processes do not influence the LNCM morphology or average particle size.

As-synthesized LNCM, Cr-LNCM, and F-LNCM materials were characterized using both laboratory XRPD and highresolution NPD. The XRPD data are shown in Figure S3 and the Rietveld refinement profiles using NPD data are shown in Figure 1a, b, and $c$. The XRPD data for all the as-prepared samples are nearly identical, with sharp reflections. Unlike similar $\mathrm{Li}_{1.2} \mathrm{Ni}_{0.13} \mathrm{Mn}_{0.54} \mathrm{Co}_{0.13} \mathrm{O}_{2}$ samples with $\mathrm{Li}: M$ varying between 1.2 and $1.8,{ }^{37} \mathrm{XRD}$ data of our samples was unable to be indexed by a monoclinic $C 2 / \mathrm{m}$ space group, and instead was indexed to a hexagonal phase with $R \overline{3} \mathrm{~m}$ space group, in agreement with other work. ${ }^{10}$ In addition to welldefined sharp peaks, the appearance of a broad feature at $20-22^{\circ} 2 \theta$ was observed, as consistent with other work. ${ }^{6-10}$ The ratio of the $R \overline{3} \mathrm{~m}$ phase 003 and 104 reflection intensities is calculated to be nearly unity, which indicates that the main phase is a typical layered structure with a low level of $\mathrm{Li} / \mathrm{Ni}$ cation mixing, in which the (003) plane is shared by all metal ions and the (104) plane is occupied by all the elements in the material. The clear splitting of the 006 and 102 reflections as well as the 018 and 110 reflections, characteristic for the $R \overline{3} m$ layered structure, is observed, further evidencing low levels of cation mixing. ${ }^{38,39}$ Whilst the NPD data of all samples could be indexed to a solely monoclinic $C 2 / \mathrm{m}$ space group, as informed by our XRPD data, a phase with a $R \overline{3} m$ layered structure was used initially to model the NPD data for all samples. The $R \overline{3} \mathrm{~m}$ layered structure described most reflections of the NPD data except for those at $\sim 44-45^{\circ}$ and $\sim 112^{\circ}$ in $2 \theta$, which are indexed by the $040 / 22 \overline{1}$ and the $22 \overline{5} / 082 / 51 \overline{1} / 280$ reflections, respectively, of the monoclinic $\mathrm{Li}_{2} \mathrm{MnO}_{3}$ phase (as shown for LNCM in Figures S4 and S5). Therefore, the only model that adequately describes both our XRD and NPD data of LNCM, Cr-LNCM, and F-LNCM samples is a two phase composition with a main $\mathrm{Li} M \mathrm{O}_{2}$ phase with $R \overline{3} \mathrm{~m}$ space group ${ }^{10}$ and a second $\mathrm{Li}_{2} \mathrm{MnO}_{3}$ phase with $C 2 / \mathrm{m}$ space group. ${ }^{6} 9$ Rietveld refinement of structural models containing the $\mathrm{Li} M \mathrm{O}_{2}$ and $\mathrm{Li}_{2} \mathrm{MnO}_{3}$ phases against the NPD data reveal a weight ratio of $\sim 4: 1$ for these phases, respectively, and excluding the $\mathrm{Li}_{2} \mathrm{MnO}_{3}$ phase from the structural model of the NPD data causes the $R_{\mathrm{wp}}$ figure of merit to rise substantially, from $\sim 4.6 \%$ to $11.7 \%$ for the LNCM sample data. The contributions from the individual phases to the final refinement profile are shown in Figure S5. The twophase nature of these composite electrodes is in good agreement with previous work demonstrating that bulk $\mathrm{Li}_{1+\mathrm{z}} \mathrm{Ni}_{\mathrm{x}} \mathrm{Co}_{1-\mathrm{x}-\mathrm{y}-\mathrm{z}} \mathrm{Mn}_{\mathrm{y}} \mathrm{O}_{2}$ commonly presents as $\mathrm{Li} M \mathrm{O}_{2}$ particles intergrown with a $\mathrm{Li}_{2} \mathrm{MnO}_{3}$ phase. . $^{8,11}$

The crystal structure details of the $R \overline{3} m$ and $C 2 / m$ phases obtained from Rietveld refinement using the highresolution NPD data are provided in Table 2 and Table S1, respectively. $\mathrm{Li} M \mathrm{O}_{2}$ and $\mathrm{Li}_{2} \mathrm{MnO}_{3}$ in the LNCM, Cr-LNCM, and F-LNCM samples remain in a $\sim 4: 1$ weight ratio, respectively. The undoped LCNM is found to be of formula 
0.15(8) $\mathrm{Li}_{2} \mathrm{MnO}_{3} .0 .85(8) \mathrm{Li}_{1.21(4)} \mathrm{Ni}_{0.27(4)} \mathrm{Co}_{0.13(3)} \mathrm{Mn}_{0.39(3)} \mathrm{O}_{2}$. NPD data analysis of the doped materials revealed the monoclinic $\mathrm{Li}_{2} \mathrm{MnO}_{3}$ phase to retain the same lattice parameters (within 1 standard error) as that of the pristine LNCM material. Within the $R \overline{3} m$ layered $\mathrm{Li} M \mathrm{O}_{2}$ phase, the $c$ lattice parameter increases on doping with $\mathrm{F}$, differing by more than 4 standard errors from the undoped material. Partial substitution of $\mathrm{F}$ for $\mathrm{O}$ within the $\mathrm{Li} M \mathrm{O}_{2}$ layered phase is expected to lead to charge deficiency and a consequential decrease in the attraction between $M$ (and Li) and 0 , resulting in an expansion of the $M(\mathrm{Li}) \mathrm{O}_{6}$ octahedron and an increase in the $c$ lattice parameter, in good agreement with our findings and those of Kageyama et al. ${ }^{30}$ The similar neutron coherent scattering lengths of $\mathrm{F}$ and $\mathrm{O}$ (5.6 and $5.8 \times 10^{-15} \mathrm{~m}$, respectively) complicate the crystallographic determination of $\mathrm{F}$ within the material phases. Inclusion of $5 \% \mathrm{~F}$ at either $\mathrm{O}$ site of the monoclinic $\mathrm{Li}_{2} \mathrm{MnO}_{3}$ phase or at the $\mathrm{O}$ site of the layered $\mathrm{Li} M \mathrm{O}_{2}$ phase did not change significantly the fit of the model to the NPD data of F-LNCM. As guided by the expected lattice parameter response, Rietveld refinement of the $\mathrm{Li} M \mathrm{O}_{2}$ phase with $5 \% \mathrm{~F}$ at the 0 site yielded a site occupancy factor in agreement with the nominal synthetic doping level. Hence, the best model of the NPD data is with $\mathrm{F}$ doping at the 0 site of the $\mathrm{Li} M \mathrm{O}_{2}$ phase forming a material of formula $0.15(16) \mathrm{Li}_{2} \mathrm{MnO}_{3}$. $0.85(16) \mathrm{Li}_{1.20(5)} \mathrm{Ni}_{0.24(5)} \mathrm{Co}_{0.13(4)} \mathrm{Mn}_{0.43(4)} \mathrm{O}_{1.90(6)} \mathrm{F}_{0.10(6)}$. The lattice parameters of both $\mathrm{Li} M \mathrm{O}_{2}$ and $\mathrm{Li}_{2} \mathrm{MnO}_{3}$ phases are relatively unchanged on $\mathrm{Cr}$ doping, a result consistent with the similar ionic radius of $\mathrm{Cr}^{3+}$ compared to the average of $\mathrm{Ni}^{2+}, \mathrm{Co}^{3+}$, and $\mathrm{Mn}^{4+} .{ }^{40}$ Although NPD yields excellent contrast between the transition-metals, the high level of codoping still presents an obstacle for the determination of $\mathrm{Cr}$ as it closely approaches the limit of detection (about $1 \%)$ of the technique. As limited by the estimated standard error for site occupancy factors, we tested several models for the inclusion of $\mathrm{Cr}$ within the two phases of the $\mathrm{Cr}$ LNCM sample against the NPD data. Excluding $\mathrm{Cr}$ altogether or including $\mathrm{Cr}$ at the $\mathrm{Li}$ site within the layered $\mathrm{Li} M \mathrm{O}_{2}$ phase and the $\mathrm{Mn}$ site within the monoclinic $\mathrm{Li}_{2} \mathrm{MnO}_{3}$ phase, all caused an increase in the goodness of fit of the model to the NPD data. The best description of the data was found by a model with $\mathrm{Cr}$ at the transition metal site (3a) within the main layered phase. The refined site occupancy factor for $\mathrm{Cr}$ at this site yields a composition that is consistent with both the nominal concentration of the dopant in the synthesis and the ICP-AES results (Table 1), indicating a material composition with formula 0.15(9) $\mathrm{Li}_{2} \mathrm{MnO}_{3} .0 .85(9) \mathrm{Li}_{1.25(5)} \mathrm{Ni}_{0.26(5)} \mathrm{Co}_{0.11(4)} \mathrm{Mn}_{0.38(4)} \mathrm{Cr}_{0.01(4)} \mathrm{O}_{2}$. Given the challenges of structural characterization of such low-level dopants, we cannot rule out the possibility that minute amounts of $\mathrm{F}$ and $\mathrm{Cr}$ may be present in the monoclinic $\mathrm{Li}_{2} \mathrm{MnO}_{3}$ phase. The LNCM, Cr-LNCM, and F-LNCM materials are nearly indistinguishable in terms of their phase ratio, level of $\mathrm{Li} / \mathrm{Ni}$ cation mixing in the $\mathrm{Li} M \mathrm{OO}_{2}$ phase, particle size, or morphology.

Table 1. Molar fraction of elements from ICP-AES.

\begin{tabular}{cccccc}
\hline \multicolumn{6}{c}{$\times 100 \%$ (molar.) } \\
\cline { 2 - 4 } & $\mathrm{Li}$ & $\mathrm{Ni}$ & $\mathrm{Mn}$ & $\mathrm{Co}$ & $\mathrm{Cr}$ \\
\hline
\end{tabular}

\begin{tabular}{cccccc}
\hline LNCM & $0.586(11)$ & $0.112(2)$ & $0.244(5)$ & $0.058(1)$ & \\
Cr-LNCM & $0.585(11)$ & $0.115(2)$ & $0.236(5)$ & $0.056(1)$ & $0.0070(1)$ \\
F-LNCM & $0.584(11)$ & $0.112(2)$ & $0.246(5)$ & $0.058(1)$ & \\
\hline
\end{tabular}

Table 2. Crystallographic details of the $R \overline{3} m \mathrm{LiMO}$ phase in LNCM, Cr-LNCM, and F-LNCM samples obtained using high-resolution NPD. SOF = site occupancy factor and $U_{\text {iso }}=$ isotropic atomic displacement parameter.

\begin{tabular}{ccccccc}
\hline \multicolumn{7}{c}{$\mathrm{Li}_{1.21(4)} \mathrm{Ni}_{0.27(4)} \mathrm{Co}_{0.13(3)} \mathrm{Mn}_{0.39(3)} \mathrm{O}_{2}$} \\
\multicolumn{7}{c}{$c / a=4.9839(6)$, volume $=100.98(1) \AA^{3}$} \\
\hline Atom & Site & $\mathrm{x}$ & $\mathrm{y}$ & $\mathrm{z}$ & $\mathrm{U}_{\text {iso }}\left(\AA^{2}\right)$ & $\mathrm{SOF}$ \\
\hline $\mathrm{Li}$ & $3 b$ & 0 & 0 & $1 / 2$ & $0.01^{\#}$ & $0.941(4)^{*}$ \\
$\mathrm{Ni}$ & $3 b$ & 0 & 0 & $1 / 2$ & $0.01^{\#}$ & $0.059(4)^{*}$ \\
$\mathrm{Li}$ & $3 a$ & 0 & 0 & 0 & $0.01^{\#}$ & $0.27(3)^{* *}$ \\
$\mathrm{Ni}$ & $3 a$ & 0 & 0 & 0 & $0.01^{\#}$ & $0.21(3)^{* *}$ \\
$\mathrm{Mn}$ & $3 a$ & 0 & 0 & 0 & $0.01^{\#}$ & $0.39(3)^{* *}$ \\
$\mathrm{Co}$ & $3 a$ & 0 & 0 & 0 & $0.01^{\#}$ & $0.13(3)^{* *}$ \\
$\mathrm{O}$ & $6 c$ & 0 & 0 & $0.2590(1)$ & $0.061(4)$ & 1 \\
\hline
\end{tabular}

$*, * *$ constrained to sum to unity, \# fixed.

\begin{tabular}{|c|c|c|c|c|c|c|}
\hline \multicolumn{7}{|c|}{$\begin{array}{c}\mathrm{Li}_{1.25(5)} \mathrm{Ni}_{0.26(5)} \mathrm{Co}_{0.11(4)} \mathrm{Mn}_{0.38(4)} \mathrm{Cr}_{0.01(4)} \mathrm{O}_{2} \\
\text { Lattice parameter } a=2.8619(5) \AA \text { and } c=14.256(1) \AA \text {, } \\
\quad c / a=4.9813(6), \text { volume }=101.11(2) \AA^{3}\end{array}$} \\
\hline Atom & Sites & $\mathrm{x}$ & $y$ & $\mathrm{z}$ & $\mathrm{U}_{\text {iso }}\left(\AA^{2}\right)$ & SOF \\
\hline $\mathrm{Li}$ & $3 b$ & 0 & 0 & $1 / 2$ & $0.01^{\#}$ & $0.966(3)^{*}$ \\
\hline $\mathrm{Ni}$ & $3 b$ & 0 & 0 & $1 / 2$ & $0.01^{\#}$ & $0.034(3)^{*}$ \\
\hline $\mathrm{Li}$ & $3 a$ & 0 & 0 & 0 & $0.01^{\#}$ & $0.28(4) * *$ \\
\hline $\mathrm{Ni}$ & $3 a$ & 0 & 0 & 0 & $0.01^{\#}$ & $0.23(4)^{* *}$ \\
\hline $\mathrm{Mn}$ & $3 a$ & 0 & 0 & 0 & $0.01^{\#}$ & $0.38(4)^{* *}$ \\
\hline Co & $3 a$ & 0 & 0 & 0 & $0.01^{\#}$ & $0.11(4)^{* *}$ \\
\hline $\mathrm{Cr}$ & $3 a$ & 0 & 0 & 0 & $0.01^{\#}$ & $0.01(4)^{* *}$ \\
\hline $\mathrm{O}$ & $6 c$ & 0 & 0 & $0.2583(1)$ & $0.005(1)$ & 1 \\
\hline \multicolumn{7}{|c|}{$*, * *$ constrained to sum to unity, \# fixed. } \\
\hline \multicolumn{7}{|c|}{$\begin{array}{l}\mathrm{Li}_{1.20(5)} \mathrm{Ni}_{0.24(5)} \mathrm{Co}_{0.13(4)} \mathrm{Mn}_{0.43(4)} \mathrm{O}_{1.90(6)} \mathrm{F}_{0.10(6)} \\
\text { tice parameter } a=2.8686(6) \AA \text { and } c=14.295(1) \AA \text {, } \\
\quad c / a=4.9832(6), \text { volume }=101.87(2) \AA^{3}\end{array}$} \\
\hline Atom & Sites & $\mathrm{x}$ & $\mathrm{y}$ & $\mathrm{z}$ & $\mathrm{U}_{\text {iso }}\left(\AA^{2}\right)$ & SOF \\
\hline $\mathrm{Li}$ & $3 b$ & 0 & 0 & $1 / 2$ & $0.01^{\#}$ & $0.960(3)^{*}$ \\
\hline $\mathrm{Ni}$ & $3 b$ & 0 & 0 & $1 / 2$ & $0.01^{\#}$ & $0.040(4)^{*}$ \\
\hline $\mathrm{Li}$ & $3 a$ & 0 & 0 & 0 & $0.01^{\#}$ & $0.24(4) * *$ \\
\hline $\mathrm{Ni}$ & $3 a$ & 0 & 0 & 0 & $0.01^{\#}$ & $0.20(4)^{* *}$ \\
\hline Mn & $3 a$ & 0 & 0 & 0 & $0.01^{\#}$ & $0.43(4) * *$ \\
\hline $\mathrm{Co}$ & $3 a$ & 0 & 0 & 0 & $0.01^{\#}$ & $0.13(4)^{* *}$ \\
\hline $\mathrm{O}$ & $6 c$ & 0 & 0 & $0.2584(1)$ & $0.001(1)$ & $0.95(3) * * *$ \\
\hline F & $6 c$ & 0 & 0 & $0.2584(1)$ & $0.001(1)$ & $0.05(3)^{* * *}$ \\
\hline
\end{tabular}



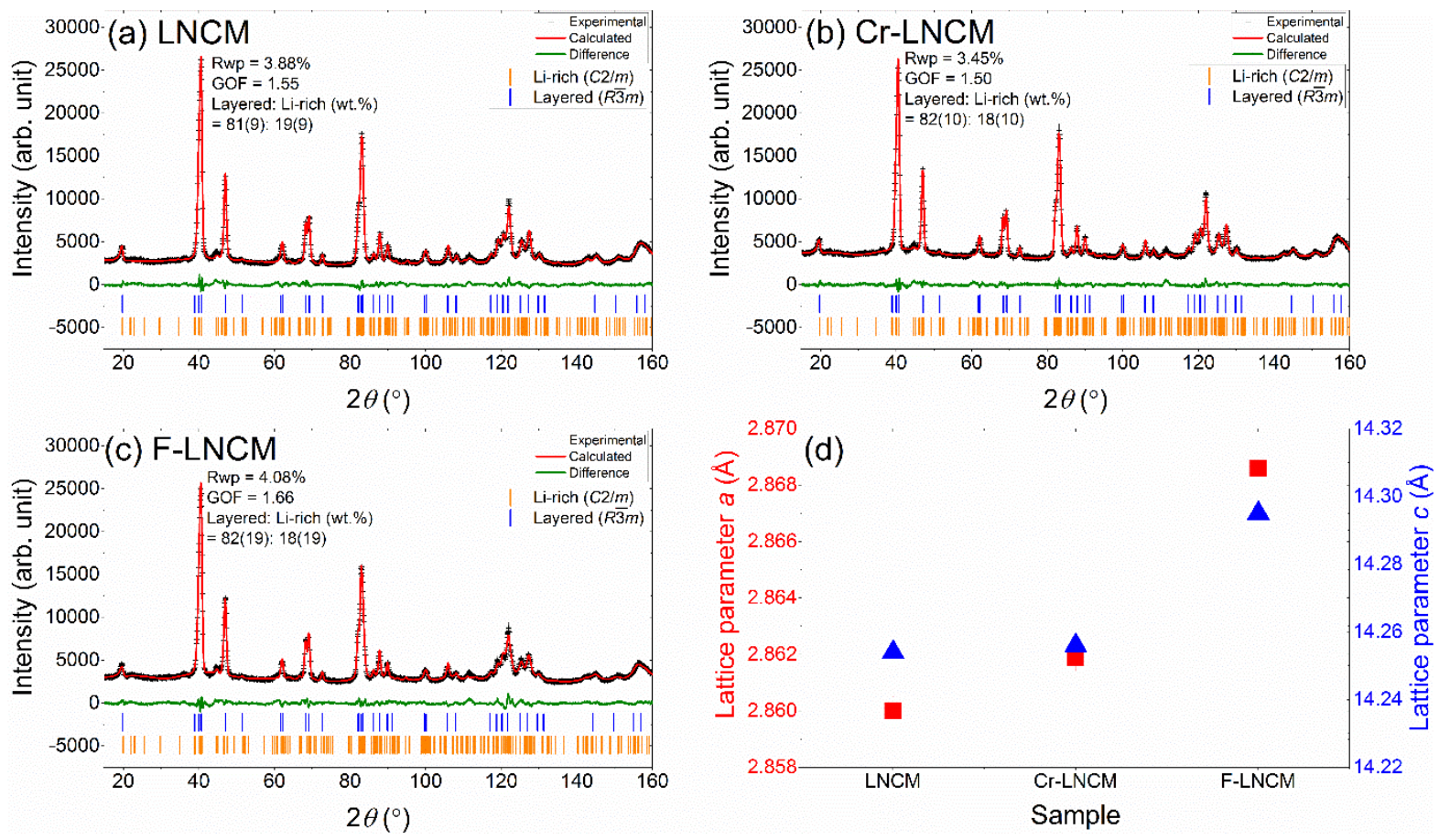

Figure 1. Final Rietveld refinement profiles using NPD data of (a) LNCM, (b) Cr-LNCM, and (c) F-LNCM powders. (d) Refined lattice parameters $a$ and $c$ of the $\mathrm{Li}_{M} \mathrm{O}_{2}$ phase with errors smaller than the points.

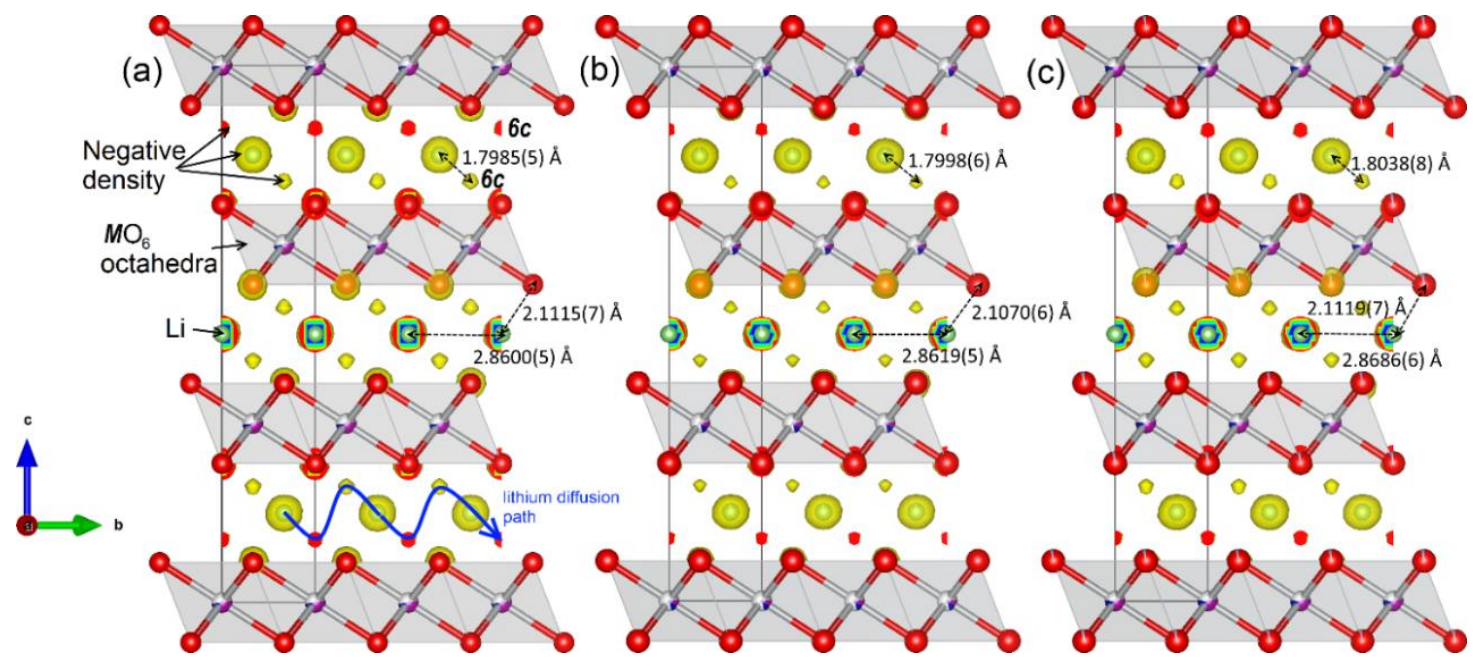

Figure 2. Fourier-difference maps obtained from high-resolution NPD showing negative nuclear density (surrounding $6 c$ sites) overlaid with the refined structure for the $\mathrm{LiMO}$ phase in LNCM (a), Cr-LNCM (b), and F-LNCM (c). The possible Li jump-diffusion path is shown by a blue line. The iso-surface level is $-0.17 \mathrm{fm} / \AA$.

It is generally accepted that lithium ions diffuse along the $a b$ plane within the $R \overline{3} m$ phase. ${ }^{41}$ We study the lithium diffusion pathway by examining nuclear density arising from the lithium, obtained by Fourier-difference methods using high resolution NPD data and the refined $R \overline{3} m$ struc- ture with lithium at $3 b$ sites removed. The nuclear density arising from Li overlaid with the refined $R \overline{3} m$ structure (Figure 2) suggests that in all three electrodes lithium diffuses between adjacent octahedral $3 b$ sites via $6 c$ tetrahedral sites. This mechanism is similar to the so-called tetra- 
hedral site hopping reported for such $R \overline{3} m$ electrodes $^{41}$ in which $6 c$ tetrahedral sites located at $(2 / 3,1 / 3, \sim 0.45)$ lower the energy barrier for jump-diffusion between $3 b$ sites in a similar manner to that reported for sodium within 03-type electrodes. ${ }^{42}$ First-principle calculations ${ }^{41}$ also suggested the existence of such interstitial tetrahedral sites as necessary to lower the energy barrier for Li diffusion along the $a b$ plane within 03-type $\mathrm{Li}_{x} \mathrm{CoO}_{2}$. Our observation of $\mathrm{Li}$ at the $6 c$ site with coordinates $(2 / 3,1 / 3, \sim$ 0.45 ) is the first reported for the LNCM material.

Lithium generally diffuses by jump-diffusion in solids where the lithium diffusion coefficient is proportional to the hop frequency and the square of the hop distance. ${ }^{43}$ The distance between the $6 c$ and $3 b$ Li sites, between neighboring $3 b$ Li sites, as well as $\mathrm{Li}-\mathrm{O}$ and $M-\mathrm{O}$ bond lengths, are summarized in Table 3. In LNCM, the $\mathrm{Li}^{3 b}-\mathrm{Li}^{3 b}$ and $\mathrm{Li}^{3 b}-\mathrm{Li}^{6 c}$ jump distances are increased by both $\mathrm{Cr}$ and F-doping, but are largest for the anionic doping case. For lithium to diffuse within the $a b$ plane, its interaction with oxygen needs to be broken. Bond lengths are inversely proportional to strength, ${ }^{44,45}$ and the hop frequency for lithium is expected to increase with increasing Li-O distance. The Li-O bond length in LNCM is shortened by $\mathrm{Cr}-$ doping and relatively-unaffected by $\mathrm{F}$ doping. Taken together, these differences predict increased Li diffusion in F- and Cr-LNCM, expected to be largest in F-LNCM.

Table 3. Li-O and $M-O$ bond lengths and distance between $\mathrm{Li}$ at various neighboring sites in $\mathrm{LNCM}, \mathrm{Cr}-\mathrm{LNCM}$, and F-LNCM.

\begin{tabular}{c|ccccc}
\hline & $\begin{array}{c}\text { LNCM } \\
(\AA)\end{array}$ & $\begin{array}{c}\text { Cr-LNCM } \\
(\AA)\end{array}$ & $\begin{array}{c}\text { Change } \\
(\%)\end{array}$ & $\begin{array}{c}\text { F-LNCM } \\
(\mathbf{\AA})\end{array}$ & $\begin{array}{c}\text { Change } \\
(\%)\end{array}$ \\
\hline $\mathrm{Li}-\mathrm{O}$ & $2.1115(7)$ & $2.1070(6)$ & $-0.21312(9)$ & $2.1119(7)$ & $0.018944(9)$ \\
$M-\mathrm{O}$ & $1.9621(6)$ & $1.9683(5)$ & $0.3159(1)$ & $1.9728(7)$ & $0.5453(3)$ \\
\hline $\mathrm{Li}^{3 b}-\mathrm{Li}^{3 b}$ & $2.8600(5)$ & $2.8619(5)$ & $0.06643(2)$ & $2.8686(6)$ & $0.30070(8)$ \\
$\mathrm{Li}^{3 b}-\mathrm{Li}^{6 c}$ & $1.7985(5)$ & $1.7998(6)$ & $0.07228(3)$ & $1.8038(8)$ & $0.2947(1)$ \\
\hline
\end{tabular}

Figure 3 shows similar typical initial CVs of the LNCM, CrLNCM, and F-LNCM composite electrodes within coin cells obtained at a scan rate of $0.2 \mathrm{mV} . \mathrm{s}^{-1}$ between 2.0 and $5.0 \mathrm{~V}$ ( $v s . \mathrm{Li})$. In the first charge, two main anodic peaks occurring at $\sim 4.3$ and $4.5 \mathrm{~V}$ correspond to the concomitant oxidation of $\mathrm{Ni}$ within $\mathrm{Li} M \mathrm{O}_{2}$ and the electrochemical activation of $\mathrm{Li}_{2} \mathrm{MnO}_{3}{ }^{6,9}$ In successive $\mathrm{CV}$ curves, the redox behavior of $\mathrm{Mn}$ and $\mathrm{Ni}$ are clearly observed, with the polarization between redox features in the $\mathrm{CV}$ curves similar between the samples. The redox couple $\mathrm{Co}^{3+} / \mathrm{Co}^{4+}$ is relatively insignificant, possibly due to the relatively small amount of Co present. ${ }^{46}$ Although it has been suggested that $\mathrm{Cr}^{3+}$ can be electrochemically active, ${ }^{47-50}$ we do not observe additional anodic or cathodic features in the $\mathrm{CV}$ data of Cr-LNCM. This may be due to the small amount of $\mathrm{Cr}^{3+}$, which if active, we estimate the 3-electron reaction would contribute only $\sim 13.8 \mathrm{mAh} . \mathrm{g}^{-1}$ to the battery capacity. The diffusivity of lithium during the $\mathrm{Ni}^{2+} / \mathrm{Ni}^{4+}$ oxidation process was calculated from the anodic CVs of the $2^{\text {nd }}$ cycle (Figure 4a, b, and c), where a linear relationship between the peak current and the square root of the scanning rate is found (Figure 4d). The Randles-Sevcik equation (eq. 1):

$I_{\mathrm{p}}=2.69 \times 10^{5} A \cdot C \cdot D^{1 / 2} \cdot n^{3 / 2} \cdot v^{1 / 2}$

relates the specific peak current $\left(I_{\mathrm{p}}\right.$ in ${\left.\mathrm{A} . \mathrm{g}^{-1}\right)}^{-}$to the geometrical surface area ${ }^{51}$ of the electrode $\left(A=1.70 \mathrm{~cm}^{2}\right.$, where the diameter of the electrode is $1.47 \mathrm{~cm})$, the shuttle concentration $\left(C \sim 0.0493\right.$ mol. $\mathrm{cm}^{-3}$, obtained using the molecular volume in Table 1 ), the charge-transfer number of electrons involved in the redox process $(n=2)$, the scan rate $\left(\nu\right.$ in V.s $\left.{ }^{-1}\right)$, and the lithium ion diffusion coefficient $(D$, in $\left.\mathrm{cm}^{2} \cdot \mathrm{s}^{-1}\right)$. Table 4 summarizes the calculated lithium diffusivity within coin cells containing the LNCM, Cr-LNCM, and F-LNCM composite electrodes. The lithium diffusion coefficient for all samples is of the same order of magnitude as that previously-reported for LNCM, being $\sim 10^{-11}$ $\mathrm{cm}^{2} . \mathrm{s}^{-1}{ }^{16} \mathrm{~F}-\mathrm{LNCM}$ exhibits the largest lithium diffusion coefficient of $3.7(2) \times 10^{-11} \mathrm{~cm}^{2} . \mathrm{s}^{-1}, 48(5) \%$ higher than for the pristine LNCM. This result is consistent with that predicted by the structural changes identified by high resolution NPD analysis discussed earlier.
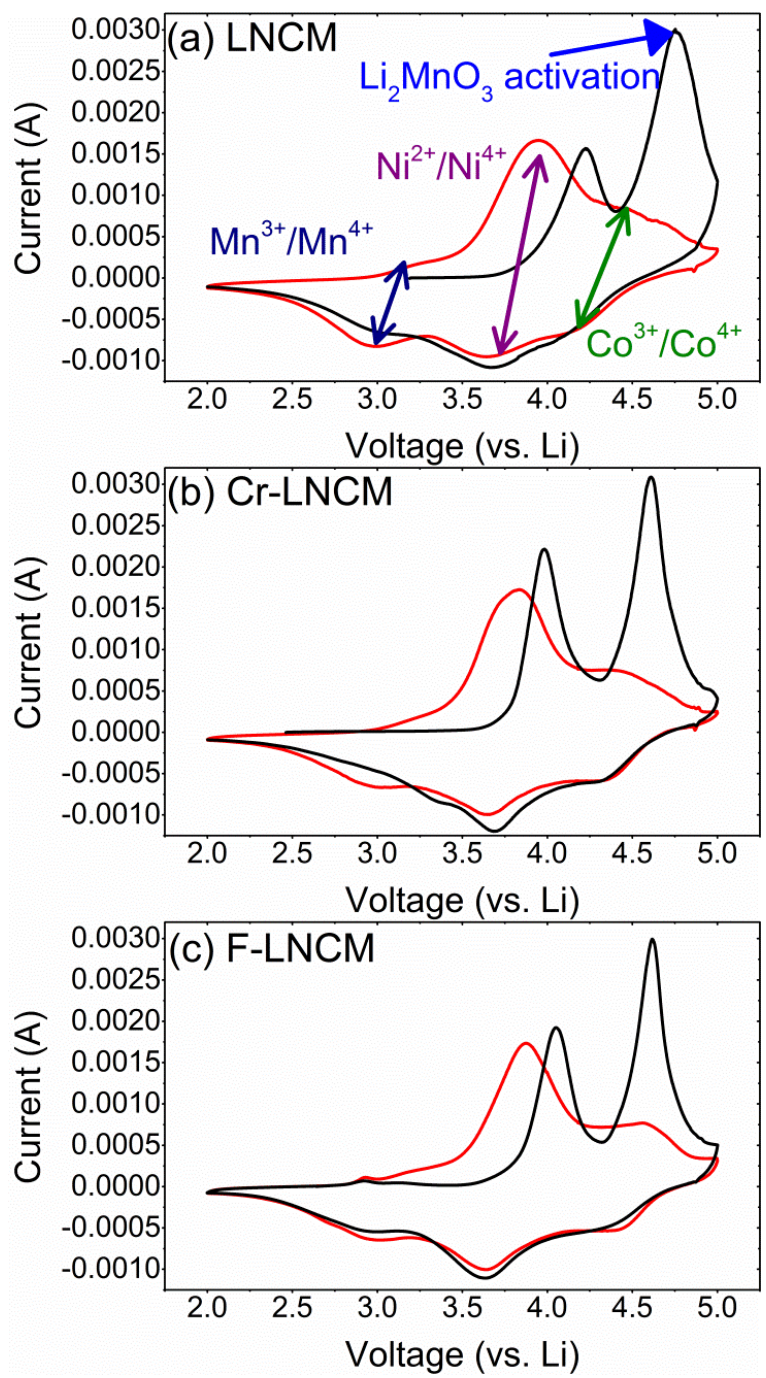

Figure 3. Cyclic voltammograms for the first two electrochemical cycles of (a) LNCM, (b) Cr-LNCM, and (c) F-LNCM containing coin-cells. Redox couples identified in green refer to the $\mathrm{Li} M \mathrm{O}_{2}$ 
phase and the feature arising from the non-reversible activation of $\mathrm{Li}_{2} \mathrm{MnO}_{3}$ is identified in blue. The first cycle is in black and the
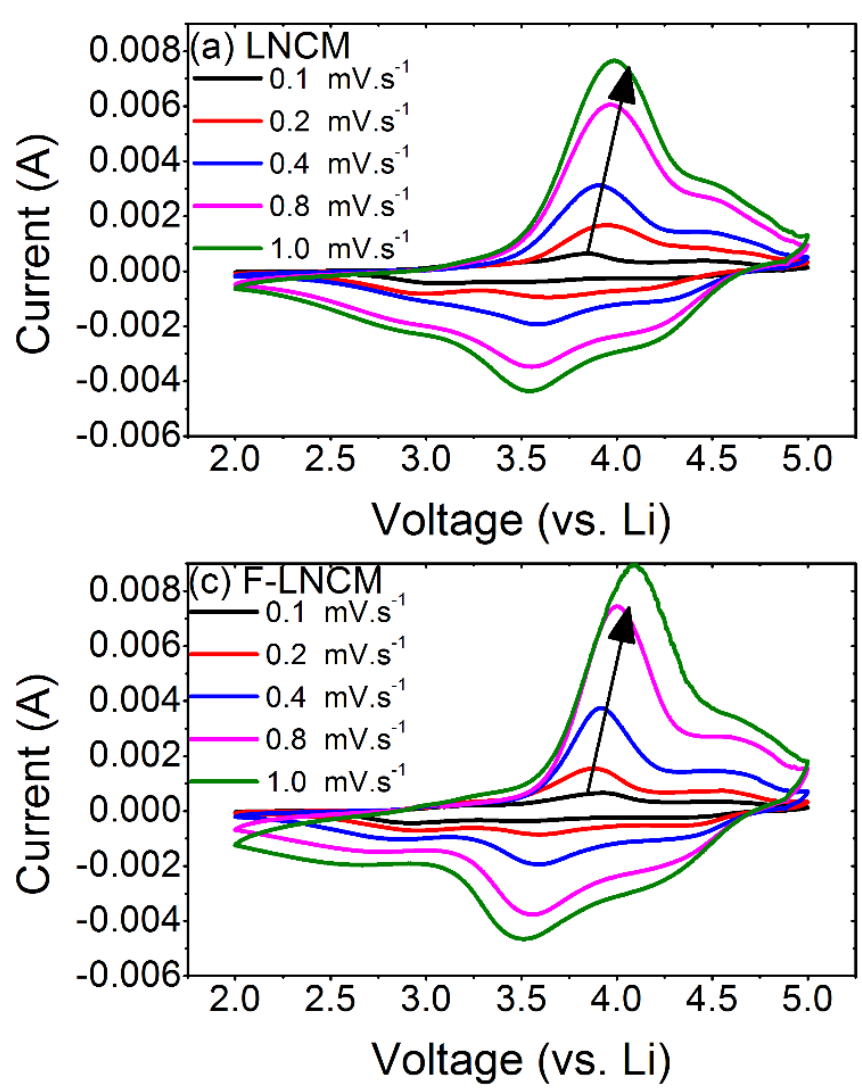

second cycle is in red.
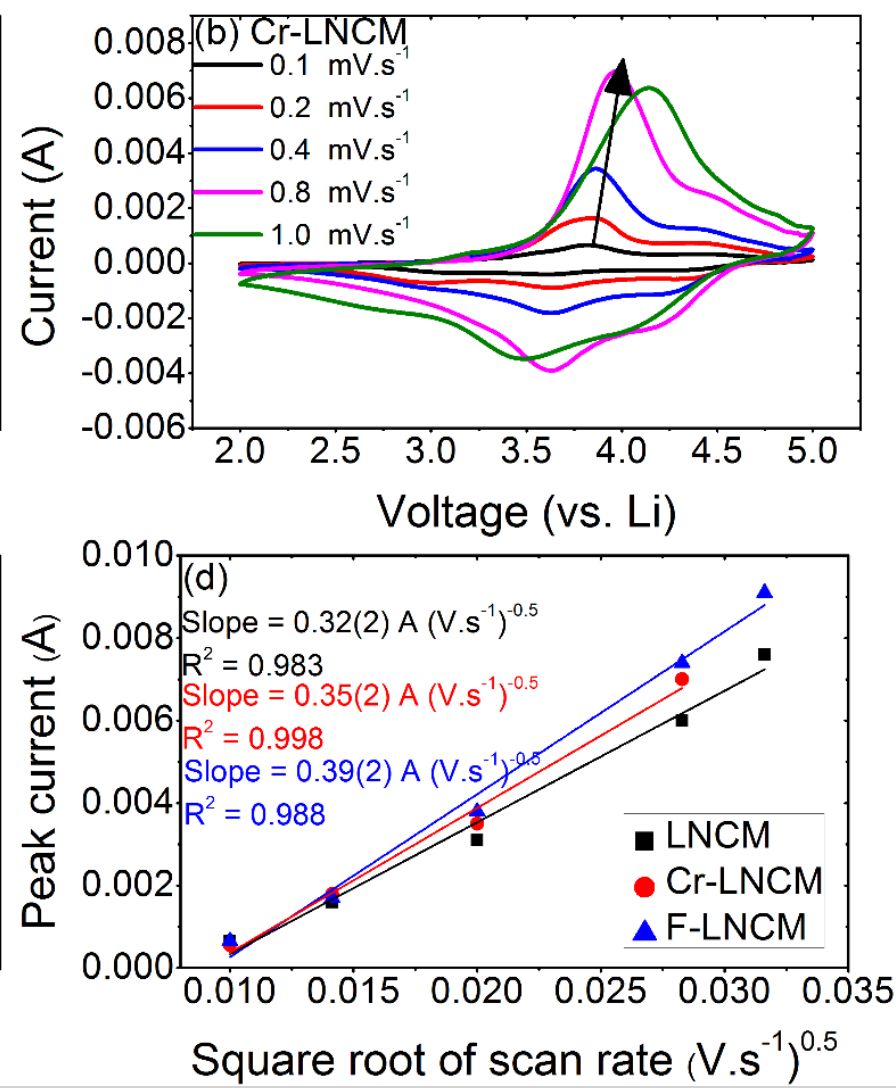

Figure 4. Cyclic voltammograms of coin-cells containing (a) LNCM, (b) Cr-LNCM, and (c) F-LNCM. (d) Peak current as a function of square root of scan rate. An anomalous point at $1.0 \mathrm{mV} . \mathrm{s}^{-1}$ for $\mathrm{Cr}-\mathrm{LNCM}$ was omitted.

Table 4. Lithium diffusivity in LNCM, Cr-LNCM, and F-LNCM containing coin cells.

\begin{tabular}{ccc}
\hline & $\times 10^{-11} \mathrm{~cm}^{2} \cdot \mathrm{s}^{-1}$ & $\%$ increase \\
\hline LNCM & $2.5(2)$ & \\
Cr-LNCM & $3.0(2)$ & $20(2)$ \\
F-LNCM & $3.7(2)$ & $48(5)$ \\
\hline
\end{tabular}

Figure 5a, b , and c show the charge-discharge curves of coin cells containing the LNCM, Cr-LNCM, and F-LNCM composite electrodes in the range $2.0-4.8 \mathrm{~V}$ ( Vs. Li) during an asymmetric cycling profile with various charge (C) and discharge (D) currents. In the first two cycles, $0.1 \mathrm{C}$ (and $0.1 \mathrm{D}$ ) was the lowest rate used to activate the $\mathrm{Li}_{2} \mathrm{MnO}_{3}$ component and gain the full capacity of the electrode in the following cycles. For LNCM (Figure 5a), the initial specific charge and discharge capacity are 340.7 and 262.3 mAh.g-1 ${ }^{-1}$ respectively, constituting a coulombic efficiency of $\sim 77 \%$. This irreversible capacity loss is revealed in the $\mathrm{CV}$ for the first cycle above $4.5 \mathrm{~V}$ by a large anodic peak, corresponding to the electrochemical activation of $\mathrm{Li}_{2} \mathrm{MnO}_{3}$ involving the evolution of oxygen. In the $2^{\text {nd }}$ cycle, the activation of $\mathrm{Li}_{2} \mathrm{MnO}_{3}$ is complete ${ }^{6,9}$ and the coulombic efficiency increases to $\sim 99 \%$, with the specific charge and discharge capacities being 266.2 and $262.8 \mathrm{mAh.g}^{-1}$, respectively. Cr-LNCM (Figure 5b) exhibits an initial specific discharge capacity of $258.1 \mathrm{mAh.g}^{-1}$ with an initial coulombic efficiency that is similar to LNCM. In contrast, FLNCM (Figure 5c) exhibits a specific discharge capacity of 274.1 mAh.g $^{-1}$ and a coulombic efficiency of $\sim 86 \%$, demonstrating the smallest initial irreversible capacity loss of the three electrodes, possibly as a result of electronic structure changes postulated to inhibit the loss of oxygen. ${ }^{30-32}$ It has been reported that a layer of $\mathrm{FePO}_{4}$ or porous $\mathrm{Co}_{3} \mathrm{O}_{4}$ coating can be used as an intermediate host to accommodate the $\mathrm{Li}^{+}$extracted from the $\mathrm{Li}_{2} \mathrm{MnO}_{3}$ matrix, with the $\mathrm{Li}^{+}$unable to intercalate back into $\mathrm{MnO}_{2}$ after forming electrochemically active $\mathrm{Li}_{\mathrm{x}} \mathrm{FePO}_{4}$ and $\mathrm{Li}_{\mathrm{x}} \mathrm{CoO}_{\mathrm{y}}{ }^{52,53}$ These coatings achieve an initial discharge capacity of $\sim 180$ mAh.g ${ }^{-1}$ without significant irreversible capacity loss. In our work, $\mathrm{F}$ doping achieves an initial discharge capacity of more than $270 \mathrm{mAh} . \mathrm{g}^{-1}$, approaching the theoretical value, and an initial irreversible capacity loss of $~ 14 \%$.

Following the initial $\mathrm{Li}_{2} \mathrm{MnO}_{3}$ activation cycle, the cells were cycled in the narrower $2.0-4.6 \mathrm{~V}$ ( Vs. Li) window to reduce the possibility of electrolyte decomposition at higher voltages. LNCM exhibited discharge capacities of 242.8, 229.0, 214.0, and 199.9 mAh.g ${ }^{-1}$ at 0.1 D, 0.2 D, 0.5 D, and $1 \mathrm{D}$, respectively, higher than those for Cr-LNCM of $230.5,211.0,192.9$, and $183 \mathrm{mAh}^{-1}{ }^{-1}$, respectively, possibly 
due to a smaller number of redox-active centers $(\sim 1.3 \%$ less than for LNCM, Table S2). In contrast, F-LNCM has a similar number of redox-active centers to LNCM, but delivered better rate performance with discharge capacities of $246.4,234.6,223.8$, and 208.9 mAh.g $^{-1}$ at $0.1,0.2,0.5$, and $1.0 \mathrm{D}$ rates, respectively, likely as a result of faster lithium diffusion through the material. During discharge, $0.1,0.2$, 0.5 , and $1.0 \mathrm{D}$ rates were chosen to compare the rate performance of the three samples.

The electrochemical performance of the LNCM, Cr-LNCM, and F-LNCM composite electrodes were further tested in full-configuration coin cells using the widely-studied $\mathrm{Li}_{4} \mathrm{Ti}_{5} \mathrm{O}_{12}$ (LTO) counter electrode, for consistency with the in operando NPD results. Compared with the Li counter electrode in half cells, LTO has a higher redox potential of $\sim 1.55 \mathrm{~V}$ (vs. Li), reducing the energy density of the battery, with this being the only difference to using a Li counter electrode. Figure 6a-c present the charge-discharge curves of these full-configuration coin cells at a $0.2 \mathrm{C}$ and $0.5 \mathrm{D}$ rates up to 200 cycles, following two formation cycles at $0.1 \mathrm{C}$ and $0.1 \mathrm{D}$ between 0.5 and $3.3 \mathrm{~V}$ (vs. LTO). Figure $6 \mathrm{~d}$ shows the corresponding capacity retention and the coulombic efficiency (data in selected cycles are shown in Table S3) up to 200 cycles. Interestingly, the Cr-LNCM and F-LNCM containing batteries exhibited the best and worst cycle performance, respectively, retaining $89.7 \%$ and $70.0 \%$ of capacity, respectively, after 200 cycles, compared with $79.4 \%$ for the undoped material. Compared to other studies, the capacity decay rate that we measure is reasonably-small for this material at such high rates. ${ }^{54}$ For example, Kobayashi et al. report a capacity retention of $\sim$ $89 \%$ after only 30 cycles at $0.1 \mathrm{C}$ for the unmodified material. ${ }^{54}$

Cycle performance is also closely connected with voltage fade (Figure 6e), which is a problem typical for these electrodes, thought to originate from a transformation to a spinel-like phase at $3 \mathrm{~V}$ (vs. Li). ${ }^{15-17}$ Voltage decay is defined as

Voltagedecay $=V\left(n^{\text {th }}\right.$ cycle $)-V\left(10^{\text {th }}\right.$ cycle $)$

Where the $\mathrm{V}$ for the $\mathrm{n}^{\text {th }}$ cycle is the average discharge potential as calculated by dividing the discharge energy by the discharge capacity. Compared with the undoped LNCM, Cr-doping has almost no effect on voltage decay up to 100 cycles and only beyond this does the Cr-doped material exhibit pronounced voltage decay. F-doping increases the severity of the voltage decay immediately relative to the undoped material. The effects of $\mathrm{Cr}$ and $\mathrm{F}$ doping on voltage decay are even more pronounced after 200 cycles, with the Cr-LNCM showing a decay of $0.081 \mathrm{~V}$ and F-LNCM showing the large decay of $0.149 \mathrm{~V}$. F-LNCM demonstrated the worst cycle performance and Cr-LNCM the best cycle performance, an interesting result. Whilst small amounts of $\mathrm{F}$ in Li-rich materials are reported to enhance cycle performance, ${ }^{30-32}$ this does not occur for our F-LNCM, possibly due to the relatively-higher doping level. For example, doping of $\mathrm{F}$ at higher levels into $\mathrm{LiNi}_{1 / 3} \mathrm{Mn}_{1 / 3} \mathrm{Co}_{1 / 3} \mathrm{O}_{2-X} \mathrm{~F}_{X}$ decreased cycle performance due to the formation of a new unstable interface, as well as structural instability arising from the non-equivalent substitution of $\mathrm{F}$ for $0 .{ }^{30}$ Similarly, within $\mathrm{Li}\left[\mathrm{Li}_{0.2} \mathrm{Mn}_{0.54} \mathrm{Ni}_{0.13} \mathrm{Co}_{0.13}\right] \mathrm{O}_{2}$ the incorporation of $5 \%$ $\mathrm{F}$ was better for cycle performance than $10 \% \mathrm{~F}$, where the F doping is reported to improve cycling stability of the layered phase through stabilization of the host structure. ${ }^{32}$ The main contribution of $\mathrm{F}$ is postulated in the material to stabilize the electrode/electrolyte interface by maintaining interfacial resistances. ${ }^{32}$ However, in our work, F-LNCM did not perform better in cycling stability tests, and this discrepancy may be due the asymmetric charge-discharge $(0.2 \mathrm{C} / 0.5 \mathrm{D})$ used in our work and/or the limited voltage range $(2.0-4.6 \mathrm{~V}$ vs. $\mathrm{Li})$ after activation of $\mathrm{Li}_{2} \mathrm{MnO}_{3}$.
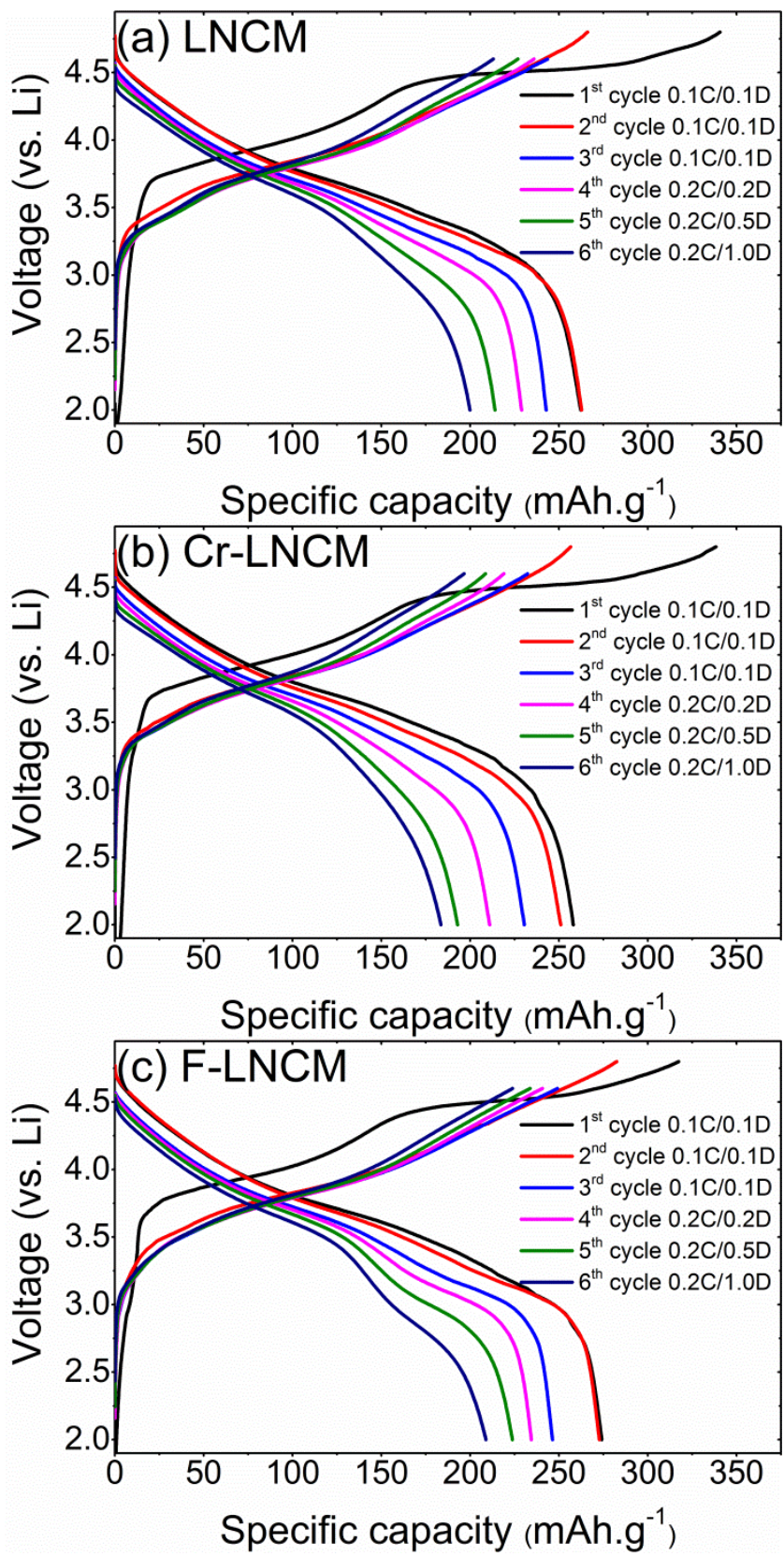

Figure 5. Capacity and rate performance of (a) LNCM, (b) $\mathrm{Cr}$ LNCM, and (c) F-LNCM within coin-cells. 

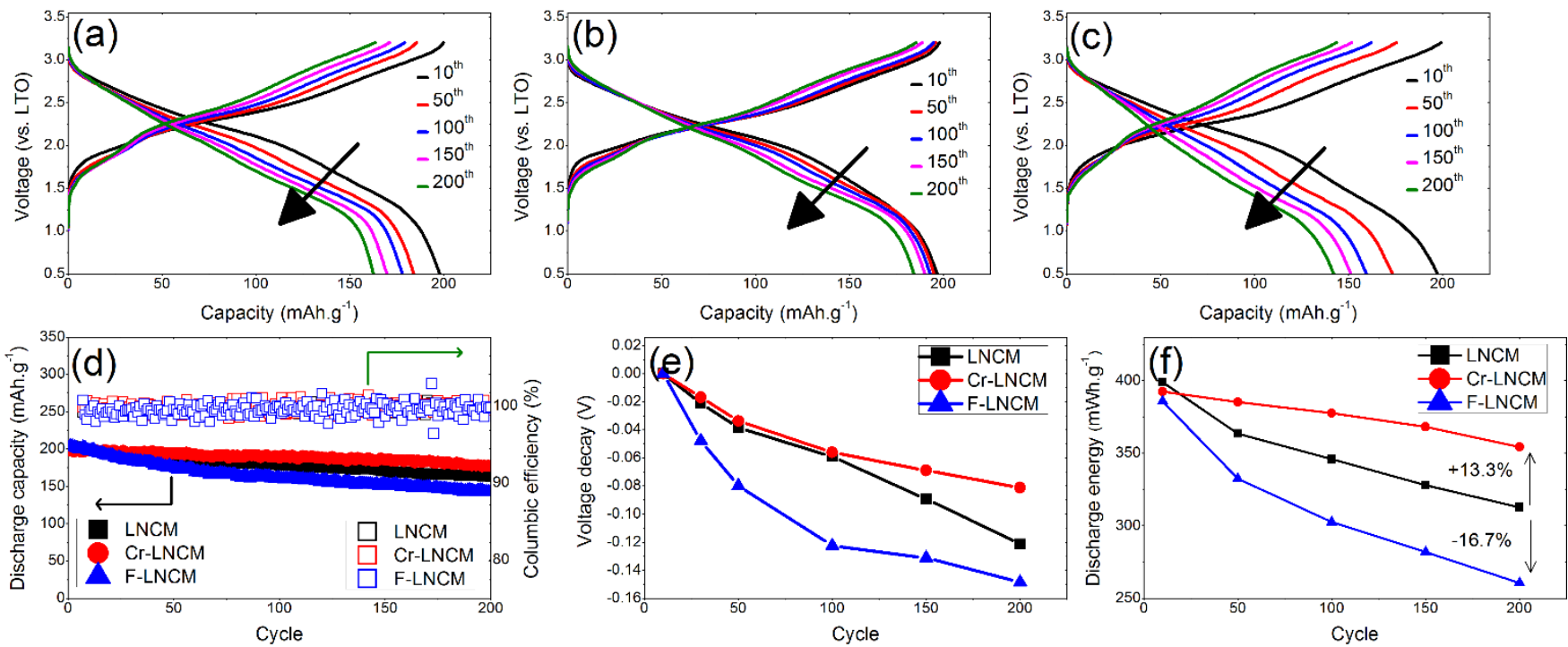

Figure 6. Charge-discharge curves of (a) LNCM, (b) Cr-LNCM, and (c) F-LNCM electrodes within full-configuration coin cells with LTO as the counter electrode. Shown also for these batteries are (d) discharge capacity, (e) voltage decay, and (f) discharge energy. Lines in (e) and (f) are guides to the eye and data are reported at selected points for clarity.
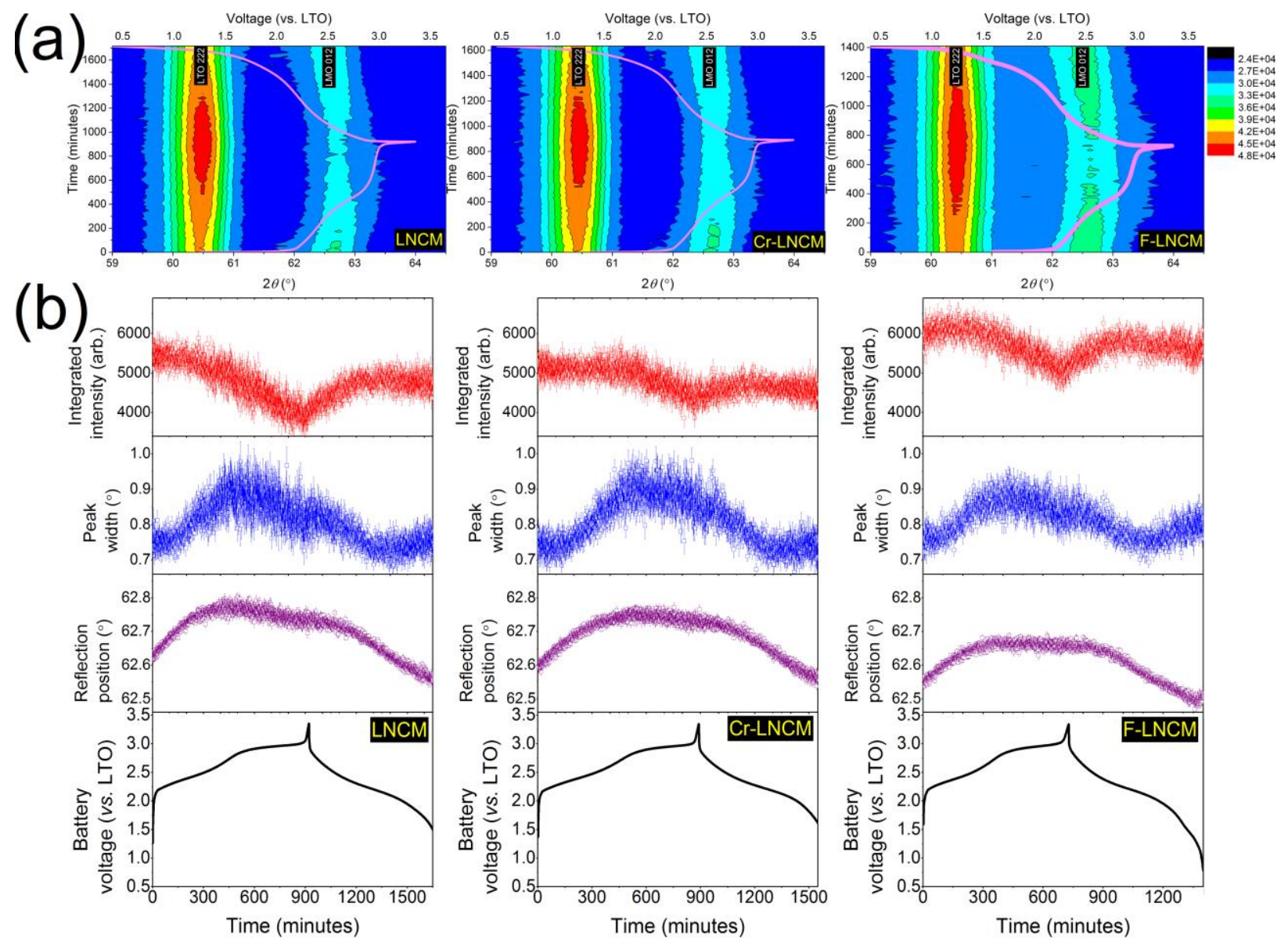

Figure 7. (a) Contour plot of in operando NPD data of LNCM-containing batteries and (b) results of single-peak fitting of the LiMO $\mathrm{O}_{2} 012$ reflection. 
To further characterize voltage decay, specific energies were calculated from the discharge curves and are shown in Figure 6f. Noting that the working potential of these batteries is $1.5 \mathrm{~V}$ less than for the equivalent half cells as a result of the LTO counter electrode, the batteries deliver $400 \mathrm{mWh} \cdot \mathrm{g}^{-1}$ at the $10^{\text {th }}$ cycle, with the undoped material delivering $\sim 313 \mathrm{mWh} . \mathrm{g}^{-1}$ after 200 cycles, compared with 355 (13.3\% higher) and 261 mWh.g ${ }^{-1}$ (16.7\% lower) for batteries containing Cr-LNCM and F-LNCM, respectively. We consider two possible mechanisms for the enhancement of structural stability by $\mathrm{Cr}$. Firstly, electrochemically active $\mathrm{Cr}^{3+}$ may be oxidized to $\mathrm{Cr}^{6+}$, with the quasireversible migration of $\mathrm{Cr}^{6+}$ at the $R \overline{3} \mathrm{~m}$ phase $3 a$ site onto the $3 b$ (Li) site mitigating voltage decay. ${ }^{47-50}$ In this scenario, the suppression of voltage decay was previously found to occur in charge but not discharge ${ }^{47}$ where our results show $\mathrm{Cr}$ doping suppressed voltage decay on discharge. The second possible mechanism for the enhancement of structure stability by $\mathrm{Cr}$ is that $\mathrm{Cr}$ is electrochemically inactive, with these inactive $\mathrm{MO}_{6}$ centers stabilizing the structure and reducing voltage decay. This possibility is consistent with the absence of features arising from the $\mathrm{Cr}^{3+} / \mathrm{Cr}^{6+}$ redox couple in our CV data and the small drop in capacity as a result of the absence of the 3-electron reaction. In light of the insensitivity of our NPD data to the migration of $\mathrm{Cr}$ into the Li layer at this low doping level (Figure S8), we cannot rule out the possibility of $\mathrm{Cr}$ redox activity in our Cr-LNMO. We note that the discrepancy between previously-reported $\mathrm{Cr}$ activity and our results may arise from material composition differences such as the fraction of the $\mathrm{Li}_{2} \mathrm{MnO}_{3}$ phase and transition metal doping, as well as differences in the upper voltage cutoff.

A comparative investigation of the phase and structural evolution of the LNCM, Cr-LNCM, and F-LNCM materials within batteries containing LTO as the counter electrode was performed using in operando neutron powder diffraction (NPD). Contour plots of data for each battery in a selected $2 \theta$ region are shown in Figure 7a, showing the evolution of the $\mathrm{Li} M \mathrm{O}_{2} 012$ and LTO 222 reflections during the first charge and discharge. The batteries were standard 18650-type with $\sim 5 \mathrm{~g}$ conventional organic electrolyte and Celgard ${ }^{\circledR}$ separator, resulting in a significant background contribution arising from the hydrogen in these components. Consequently, given the relatively-lower symmetry and smaller amount of $\mathrm{Li}_{2} \mathrm{MnO}_{3}$ in the battery, this component was not observable.

The in operando NPD data were analyzed using single peak fitting of the $\mathrm{Li} M \mathrm{O}_{2} 012$ reflection the results of which are shown in Figure 7b, and single peak fitting of the LTO 222 reflection, the results of which are shown in Figure S6. The NPD data reveal that the $\mathrm{Li} M \mathrm{O}_{2}$ phase in LNCM, Cr-LNCM, and F-LNCM electrodes exhibits a similar solid-solution type reaction during charge and discharge. Upon charging to $3.0 \mathrm{~V}$ (vs. $\mathrm{LTO}$ ), the $\mathrm{Li} M \mathrm{O}_{2} 012$ reflection position shifts to higher $2 \theta$, consistent with lattice shrinkage during lithium extraction. At $3.0 \mathrm{~V}$ (vs. LTO) and above, the $\mathrm{Li}_{2} \mathrm{MnO}_{3}$ component is activated and the $\mathrm{Li} M \mathrm{O}_{2} 012$ reflection remains nearly unchanged in position, shifting only marginally to lower $2 \theta$. On discharge to $2.5 \mathrm{~V}$ (vs. LTO), again no significant shift in position of the $\mathrm{Li} M \mathrm{O}_{2} 012$ reflection was observed. These results are similar to that reported for the undoped LNCM material by Chen et al. ${ }^{11}$

We quantify the structural response of electrodes to lithium extraction in each of the LNCM, Cr-LNCM, and F-LNCM containing batteries by examining the rate of change $\left({ }^{\circ}\right.$ per min) and maximum change $\left(^{\circ}\right)$ of the $\mathrm{Li} M \mathrm{O}_{2} 012$ reflection position. Following the first charge-discharge, the LNCM, Cr-LNCM, and F-LNCM materials exhibit reproducible charge-discharge curves in subsequent cycles, and therefore a comparison of the $\mathrm{Li} M \mathrm{O}_{2}$ structural response occurring in the first discharge between the three samples can be used to understand differences in cycle performance. Single-peak fitting of the $\mathrm{Li} M \mathrm{O}_{2} 012$ reflection in NPD data obtained during the first charge at a constant current of 1.0 A from open-circuit voltage (OCV) to $2.8 \mathrm{~V}$ (vs. LTO) reveals a rate of change of position of 4.55(7), 4.09(7), and 4.14(7) ${ }^{\circ}$ per min for LNCM, Cr-LNCM, and F-LNCM containing batteries, respectively (Figure S7). The maximum shift of the $\mathrm{Li} M \mathrm{O}_{2} 012$ reflection during this time is $0.14(1), 0.11(1)$, and $0.12(1)^{\circ}$ for LNCM, Cr-LNCM, and FLNCM containing batteries, respectively. The $\mathrm{Li} \mathrm{MO}_{2} 012$ reflection changes more slowly and less on charge in the Cr-LNCM and F-LNCM containing batteries than for the undoped LNCM containing battery. Conversely, on lithiation during discharge from 2.6 to $2.0 \mathrm{~V}$ (vs. LTO), the rate of change of the $\mathrm{Li} M \mathrm{O}_{2} 012$ reflection position was 3.22(3), $-3.28(3)$, and $-3.43(3)^{\circ}$ per min for the LNCM, CrLNCM, and F-LNCM containing batteries, respectively (Figure S7). The maximum shift of the $\mathrm{Li} \mathrm{MO}_{2} 012$ reflection during this time is $0.12(1), 0.14(1)$, and $0.15(1)^{\circ}$ for LNCM, Cr-LNCM, and F-LNCM containing batteries, respectively. The fastest and largest change in the $\mathrm{Li} M \mathrm{O}_{2} 012$ reflection position occurring during discharge therefore occurs for the F-LNCM containing battery, pointing to structural instability.

We further explore the structural changes occurring in the three LNCM electrodes by the degree of structural distortion in the transition metal oxygen octahedron of the $\mathrm{Li}$ $M \mathrm{O}_{2}$ phase by calculating the oxygen positional parameter, z. Although the NPD data do not support refinement of the oxygen positional parameter directly, it can be studied through the intensity of the $\mathrm{Li} M \mathrm{O}_{2} 012$ reflection. NPD patterns were simulated for $\mathrm{Li} M \mathrm{O}_{2}$ using the crystallographic details as shown in Table 1 with an oxygen positional parameter varying from $\mathrm{z}=0.251$ to 0.275 , establishing the relationship between the $\mathrm{Li} M \mathrm{O}_{2} 012$ reflection intensity and $\mathrm{z}$ value (Figure $8 \mathrm{a}$ and $\mathrm{b}$ ). The simulation results assume a constant oxygen level in the layered $\mathrm{Li} \mathrm{MO}_{2}$ phase, as supported by work revealing that oxygen loss occurs from the monoclinic $\mathrm{Li}_{2} \mathrm{MnO}_{3}$ phase, ${ }^{55}$ where the reflection intensity change is associated with repositioning of the 0 . We note that our previous work ${ }^{11}$ on this system revealed a reflection from the $\mathrm{MnO}_{2}$ delithiation product of $\mathrm{Li}_{2} \mathrm{MnO}_{3}$, however, we did not see this reflection in this work due to the use of hydrogenated electrolyte. Figure $8 \mathrm{c}$ depicts this octahedral distortion as $\mathrm{z}$ changes from 0.251 to 0.275 , giving rise to a change in the $0-\mathrm{M}-0$ bond angle from 89.80 to $101.34^{\circ}$. The relationship between reflection intensity and $\mathrm{z}$ value for the Cr- and F-LNCM is plotted in Figure S9. $\mathrm{The} \mathrm{Li} \mathrm{O}_{2} 012$ reflection intensity drops non-linearly with 
z, where a larger change in intensity is associated a correspondingly larger octahedral distortion. This simulation clearly reveals that the Cr-LNCM electrode, which maintains the highest $\mathrm{Li} M \mathrm{O}_{2} 012$ reflection intensity, exhibits the lowest octahedral distortion, implying that it is high structural stability underpinning its better cycle performance. Although structural instability is not necessarily implicated by a lattice change, the magnitude of expansion or contraction during lithiation/delithiation processes directly correlates with strain, which is known to lead to performance decay on cycling. The relatively-larger structural change in the $\mathrm{Li} M \mathrm{O}_{2}$ component of the F-doped electrode during discharge points to structural instability, likely explaining the poor cycle performance of this material. In contrast, whilst low-level doping of $\mathrm{Cr}$ doping does not significantly change the original lattice or enhance Li- diffusivity or capacity, it results in less structural change during cycling.

Scheme 1 summarizes the effects of $\mathrm{Cr}$ and $\mathrm{F}$ substitution on the structure and electrochemical performance of the LNCM positive electrode. In summary, $\mathrm{F}$ and $\mathrm{Cr}$ are believed to substitute into the $\mathrm{R} \overline{3} \mathrm{~m}$ layered $\mathrm{Li} M \mathrm{O}_{2}$ phase. $\mathrm{Cr}$ substitution does not have a major impact on the phase lattice parameter or lithium diffusivity through the material, but enhances cycling performance and reduces the voltage decay at the expense of a small amount of capacity. On the other hand, $\mathrm{F}$ substitution results in a significant expansion of the $\mathrm{Li} M \mathrm{O}_{2}$ phase lattice and faster lithium diffusion through the material, leading to greater capacity and rate performance. However, the cycling performance is reduced by $\mathrm{F}$ as a result of a greater structural change in the $\mathrm{Li} \mathrm{MO}_{2}$ phase during cycling.

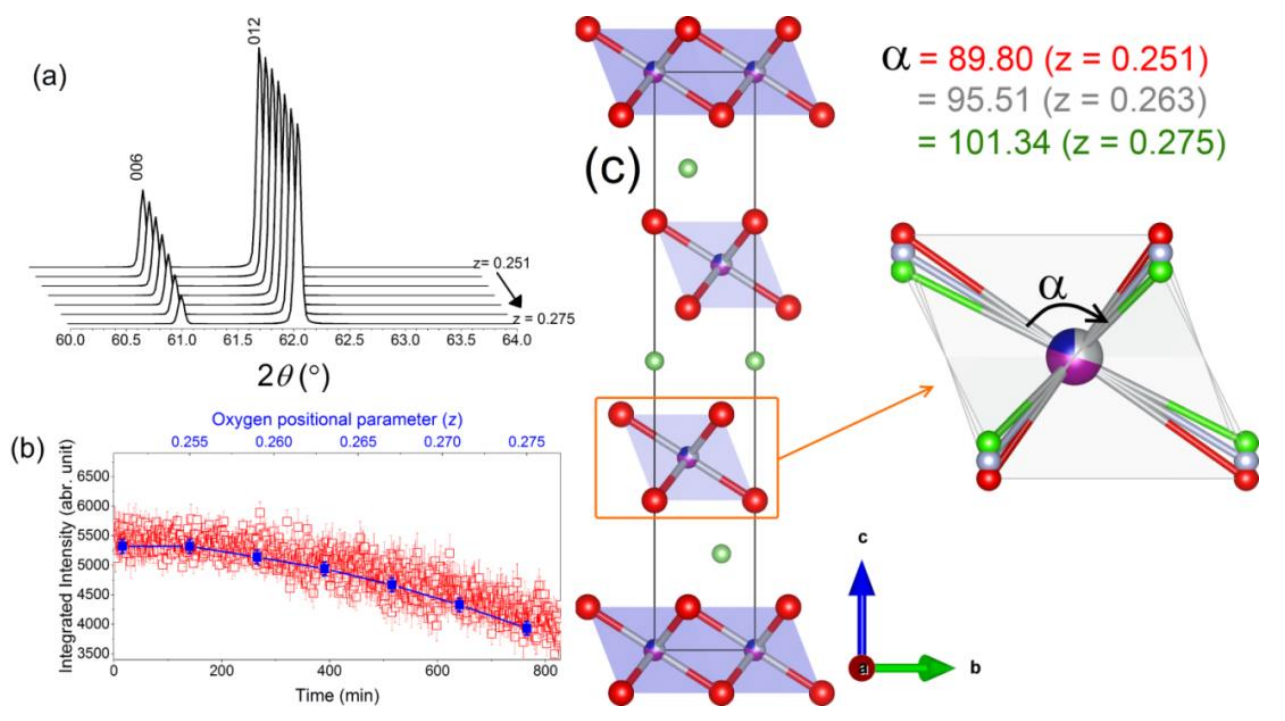

Figure 8. (a) Simulated NPD patterns (at $2.4123 \AA$ ) for $\mathrm{Li} M \mathrm{O}_{2}$ using the crystallographic details shown in Table 2 at various oxygen positional parameters $(z)$ and (b) the $\mathrm{Li} M \mathrm{O}_{2} 012$ reflection integrated intensity as a function of $z$ obtained by Gaussian peak fitting of (a). Red rectangles are the measured intensity from experimental NPD data of LNCM-containing batteries during charge and solid blue rectangles are the calculated reflection intensity. (c) Crystal structure of the $\mathrm{Li} \mathrm{O}_{2}$ phase showing the $M \mathrm{O}_{6}$ octahedron at various oxygen positional parameter values, $z$. Oxygen is depicted as red (and in (c) green and grey), with the central atom having mixed transition-metal occupancy. 


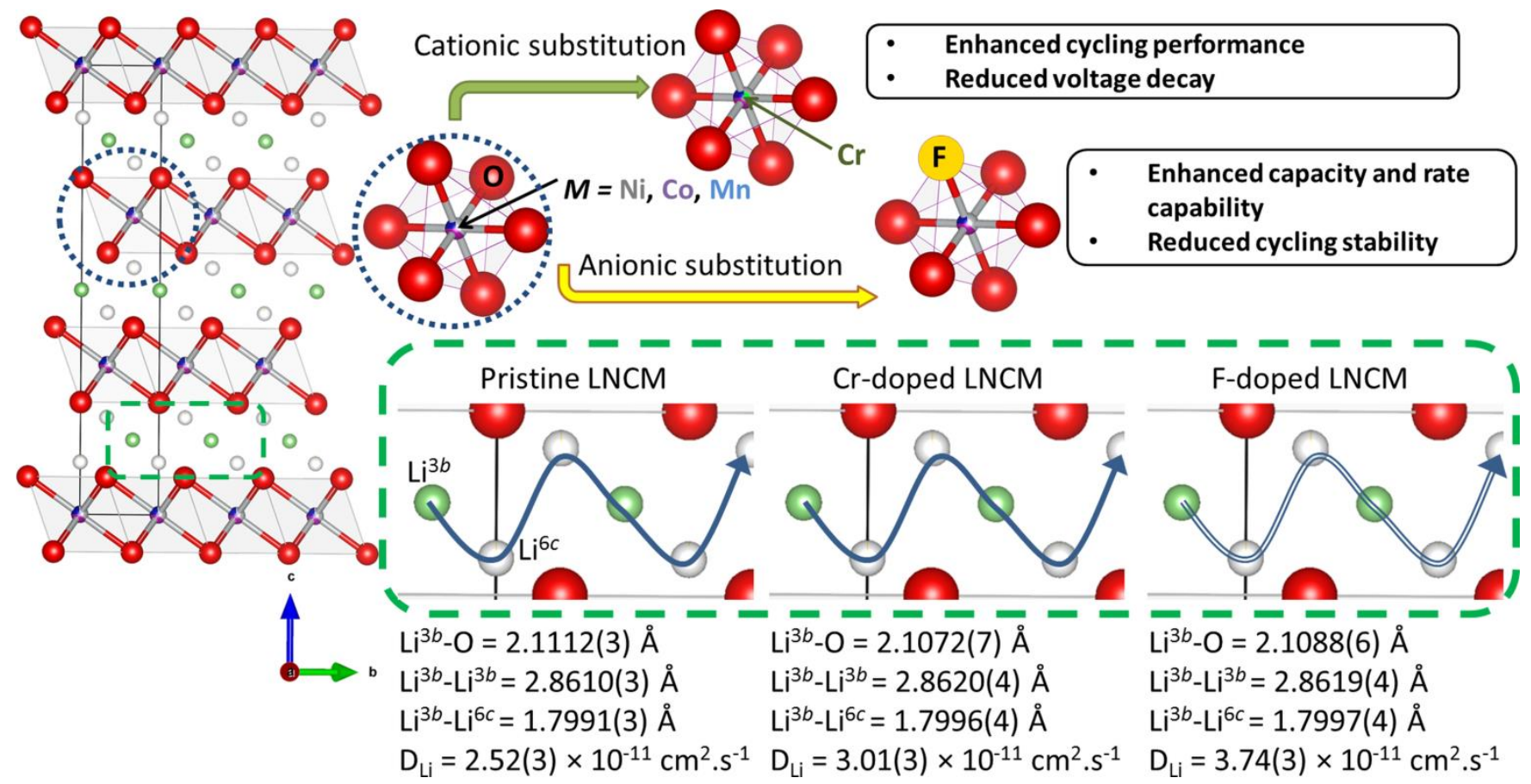

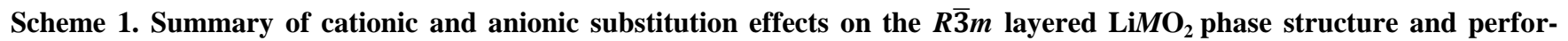
mance of the lithium-rich $\mathrm{Li}_{1+\mathrm{x}} M \mathrm{O}_{2}(M=\mathrm{Ni}$, Mn, Co) positive electrode. We note that in F-LNCM, F occupies $5 \%$ of $6 c$ sites in $\mathrm{Li} M \mathrm{O}_{2}$ and is represented schematically as 1 of 6 sites. 


\section{- CONCLUSIONS}

The effects of doping $\mathrm{Cr}$ and $\mathrm{F}$ into the lithium-rich layered metal oxide $\mathrm{Li}\left(\mathrm{Li}_{0.13} \mathrm{Ni}_{0.24} \mathrm{Co}_{0.12} \mathrm{Mn}_{0.5}\right) \mathrm{O}_{2}$ positive electrode material on battery performance and structural evolution was examined. Neutron powder diffraction revealed that doping with $2 \% \mathrm{Cr}$ and $5 \% \mathrm{~F}$ did not change the electrode phase composition of $80 \mathrm{wt} . \% R \overline{3} \mathrm{~m}$ and $20 \mathrm{wt} \% \mathrm{C} / \mathrm{m}$ space-group symmetry components, and microscopy measurements revealed that the dopants did not alter significantly the particle size or morphology of the electrode powders.

Crystallographically, structural characterization points to $\mathrm{Cr}$ and $\mathrm{F}$ doping occurring in the main layered $R \overline{3} \mathrm{~m}$ phase, with $\mathrm{Cr}$ doping at the $3 a$ transition-metal site and not significantly affecting the lattice, and F-doping at the $6 c$ oxygen site and significantly increasing the $c$ lattice parameter. Electrochemically, F-doping enhanced capacity and rate performance, postulated to occur as a result of enhanced Li diffusivity achieved by an increase in Li site hop distance. Cr-doping suppressed capacity and rate performance. However, long-cycle testing of full configuration batteries revealed very poor cycle performance of the Fdoped material, with only $64.0 \%$ capacity retention and $67.6 \%$ energy density after 200 cycles under a $0.2 \mathrm{C} / 0.5 \mathrm{D}$ asymmetric cycle profile, in contrast to the enhancement of both cycle performance and voltage decay achieved by Cr-doping. These apparently contradictory results are explained by in operando neutron powder diffraction data which revealed a structural change of the $\mathrm{Li} M \mathrm{O}_{2}$ phase that was enhanced by F-doping, suggesting structural instability on cycling, in comparison to the suppression of $\mathrm{Li} M \mathrm{O}_{2}$ structural change achieved by Cr-doping.

This work establishes the chemistry- and structurefunction relations for the lithium-rich layered metal oxide $\mathrm{Li}\left(\mathrm{Li}_{0.13} \mathrm{Ni}_{0.24} \mathrm{Co}_{0.12} \mathrm{Mn}_{0.5}\right) \mathrm{O}_{2}$ and the roles of both anionic (F) and cationic $(\mathrm{Cr})$ doping on this. Anionic substitution with $\mathrm{F}$ promotes a larger crystal lattice, resulting in faster $\mathrm{Li}$ diffusion, as well as higher capacity and rate performance. Cationic substitution with $\mathrm{Cr}$ promotes structural stability, at the expense of some capacity. Given these differences, co-doping is implicated as a possible future strategy for combining the benefits of these dopants for optimized electrochemical performance.

\section{ASSOCIATED CONTENT}

Electrochemical test results for LNCM doped with $\mathrm{Cr}$ and F (Figure S1); SEM micrographs (Figure S2) and XRPD data (Figure S3) of LNCM, Cr-LNCM, and F-LNCM particles; NPD data of LNCM shown over a select $2 \theta$ range (Figure $\mathrm{S} 4$ ); the contribution of monoclinic $\mathrm{Li}_{2} \mathrm{MnO}_{3}$ and layered $\mathrm{Li} M \mathrm{O}_{2}$ phases to the final Rietveld model of NPD data for LNCM (Figure S5); results of single-peak fitting of the LTO 222 reflection in NPD data of LNCM, Cr-LNCM, and F-LNCM-containing batteries (Figure S6); the rate of change of the $\mathrm{LiMO}_{2} 102$ reflection position in NPD data during battery discharge from $2.6 \mathrm{~V}$ (vs. LTO) (Figure S7); simulated NPD data of $\mathrm{Li} M \mathrm{O}_{2}$ with $\mathrm{Cr}$ occupying metal and $\mathrm{Li}$ sites (Figure $\mathrm{S} 8$ ); $\mathrm{LiMO}_{2} 012$ reflection integrated intensity as a function of $z$ obtained by Gaussian peak fitting (Figure S9); crystallographic details of $\mathrm{Li}_{2} \mathrm{MnO}_{3}$ obtained from Rietveld refine- ment against NPD data (Table $\mathrm{S} 1$ ); redox centers in samples from ICP-AES (Table S2); and coulombic efficiencies for the $50^{\text {th }}$, $100^{\text {th }}, 150^{\text {th }}$, and $200^{\text {th }}$ cycle (Table S3). This material is available free of charge via the Internet at http://pubs.acs.org.

\section{AUTHOR INFORMATION}

\section{Corresponding Author}

* Email: vanessa.peterson@ansto.gov.au (V.K.P.) Tel: +61 9717 9401

\section{Author Contributions}

The manuscript was written through contributions of all authors. All authors have given approval to the final version of the manuscript.

\section{ACKNOWLEDGMENT}

The authors acknowledge the support funded by Ministry of Economic Affairs (MOE) and Industrial Technology Research Institute (ITRI) and the staff members at the Australian Centre for Neutron Scattering, ANSTO for their operations support. W.K.P. is grateful to the support funded by Australian Research Council (ARC, FT160100251).

\section{ABBREVIATIONS}

NPD, neutron powder diffraction; XRPD, X-ray powder diffraction; LIB, Lithium-ion battery. PVDF, polyvinylidene difluoride; NMP, N-methyl pyrrolidinone; EC; ethylene carbonate; DMC, dimethyl carbonate; OCV, open circuit voltage; CV, cyclic voltammetry; ICP-AES, inductivelycoupled plasma - atomic emission spectrometry.

\section{REFERENCE}

(1) Goodenough, J. B.; Kim, Y., Challenges for Rechargeable Batteries. J. Power Sources 2011, 196, 6688-6694.

(2) Nitta, N.; Wu, F.; Lee, J. T.; Yushin, G., Li-Ion Battery Materials: Present and Future. Mater. Today 2015, 18, (5), 252-264.

(3) Tarascon, J. M.; Armand, M., Issues and Challenges Facing Rechargeable Lithium Batteries. Nature 2001, 414, (6861), 359-367.

(4) Tsutomu, O.; Yoshinari, M., Layered Lithium Insertion Material of $\mathrm{LiCo}_{1 / 3} \mathrm{Ni}_{1 / 3} \mathrm{Mn}_{1 / 3} \mathrm{O}_{2}$ for Lithium-Ion Batteries. Chem. Lett. 2001, 30, (7), 642-643.

(5) Yabuuchi, N.; Ohzuku, T., Novel Lithium Insertion Material of $\mathrm{LiCo}_{1 / 3} \mathrm{Ni}_{1 / 3} \mathrm{Mn}_{1 / 3} \mathrm{O}_{2}$ for Advanced Lithium-Ion Batteries. J. Power Sources 2003, 119 - 121, (0), 171-174.

(6) Boulineau, A.; Croguennec, L.; Delmas, C.; Weill, F., Reinvestigation of $\mathrm{Li}_{2} \mathrm{MnO}_{3}$ Structure: Electron Diffraction and High Resolution TEM. Chem. Mater. 2009, 21, (18), 4216-4222.

(7) Lu, Z.; Beaulieu, L. Y.; Donaberger, R. A.; Thomas, C. L.; Dahn, J. R., Synthesis, Structure, and Electrochemical Behavior of $\mathrm{Li}\left[\mathrm{Ni}_{\mathrm{x}} \mathrm{Li}_{1 / 3-2 \times / 3} \mathrm{Mn}_{2 / 3-\mathrm{x} / 3}\right] \mathrm{O}_{2}$. J. Electrochem. Soc. 2002, 149, (6), A778-A791.

(8) Yu, H.; Ishikawa, R.; So, Y.-G.; Shibata, N.; Kudo, T.; Zhou, H.; Ikuhara, Y., Direct Atomic-Resolution Observation of Two Phases in the $\mathrm{Li}_{1.2} \mathrm{Mn}_{0.567} \mathrm{Ni}_{0.166} \mathrm{Co}_{0.067} \mathrm{O}_{2}$ Cathode Material for Lithium-Ion Batteries. Angew. Chem. 2013, 125, (23), 6085-6089.

(9) Johnson, C. S.; Kim, J. S.; Lefief, C.; Li, N.; Vaughey, J. T.; Thackeray, M. M., The Significance of the $\mathrm{Li}_{2} \mathrm{MnO}_{3}$ Component in 'Composite' $\mathrm{xLi}_{2} \mathrm{MnO}_{3} .(1-\mathrm{x}) \mathrm{LiMn}_{0.5} \mathrm{Ni}_{0.5} \mathrm{O}_{2}$ Electrodes. Electrochem. Comm. 2004, 6, (10), 1085-1091.

(10) Johnson, C. S.; Li, N.; Lefief, C.; Vaughey, J. T.; Thackeray, M. M., Synthesis, Characterization and Electrochemistry 
of Lithium Battery Electrodes: $\mathrm{xLi}_{2} \mathrm{MnO}_{3} \cdot\left(_{-}\right.$ $\mathrm{x}) \mathrm{LiMn}_{0.333} \mathrm{Ni}_{0.333} \mathrm{Co}_{0.333} \mathrm{O}_{2}(0 \leq \mathrm{x} \leq 0.7)$. Chem. Mater. 2008, 20, (19), 6095-6106.

(11) Chen, C.-J.; Pang, W. K.; Mori, T.; Peterson, V. K.; Sharma, N.; Lee, P.-H.; Wu, S.-h.; Wang, C.-C.; Song, Y.-F.; Liu, R.S., The Origin of Capacity Fade in the $\mathrm{Li}_{2} \mathrm{MnO}_{3} \cdot \mathrm{Li} \mathrm{O}_{2}(M=\mathrm{Li}, \mathrm{Ni}$, Co, Mn) Microsphere Positive Electrode: An Operando Neutron Diffraction and Transmission X-ray Microscopy Study. J. Am. Chem. Soc. 2016, 138, (28), 8824-8833.

(12) Xiang, Y.; Yin, Z.; Li, X., Structural and Electrochemical Characterization of $\mathrm{Li}_{1.2} \mathrm{Ni}_{\mathrm{x}} \mathrm{Co}_{\mathrm{x}} \mathrm{Mn}_{0.8-2 \mathrm{x}} \mathrm{O}_{2}(\mathrm{x}=0.128,0.16$, and 0.2$)$ as Cathode Materials for Lithium-Ion Batteries. Ionics 2014, 20, (2), 157-162.

(13) Rozier, P.; Tarascon, J. M., Review - Li-Rich Layered Oxide Cathodes for Next-Generation Li-Ion Batteries: Chances and Challenges. J. Electrochem. Soc. 2015, 162, (14), A2490-A2499.

(14) Baggetto, L.; Mohanty, D.; Meisner, R. A.; Bridges, C. A.; Daniel, C.; Wood Iii, D. L.; Dudney, N. J.; Veith, G. M., Degradation Mechanisms of Lithium-Rich Nickel Manganese Cobalt Oxide Cathode Thin Films. RSC Adv. 2014, 4, (45), 23364-23371.

(15) Lee, E.-S.; Manthiram, A., Smart Design of Lithium-Rich Layered Oxide Cathode Compositions with Suppressed Voltage Decay. J. Mater. Chem. A 2014, 2, (11), 3932-3939.

(16) Song, B.; Liu, Z.; Lai, M. O.; Lu, L., Structural Evolution and the Capacity Fade Mechanism upon Long-Term Cycling in LiRich Cathode Material. Phys. Chem. Chem. Phys. 2012, 14, (37), 12875-12883.

(17) Sathiya, M.; Abakumov, A. M.; Foix, D.; Rousse, G.; Ramesha, K.; Saubanère, M.; Doublet, M. L.; Vezin, H.; Laisa, C. P.; Prakash, A. S.; Gonbeau, D.; VanTendeloo, G.; Tarascon, J. M., Origin of Voltage Decay in High-Capacity Layered Oxide Electrodes. Nat Mater 2015, 14, (2), 230-238.

(18) Yang, J.; Xiao, L.; He, W.; Fan, J.; Chen, Z.; Ai, X.; Yang, H.; Cao, Y., Understanding Voltage Decay in Lithium-Rich Manganese-Based Layered Cathode Materials by Limiting Cutoff Voltage. ACS Appl. Mater. Interfaces 2016, 8, (29), 18867-18877.

(19) Ito, A.; Li, D.; Sato, Y.; Arao, M.; Watanabe, M.; Hatano, M.; Horie, H.; Ohsawa, Y., Cyclic Deterioration and Its Improvement for Li-Rich Layered Cathode Material $\mathrm{Li}\left[\mathrm{Ni}_{0.17} \mathrm{Li}_{0.2} \mathrm{Co}_{0.07} \mathrm{Mn}_{0.56}\right] \mathrm{O}_{2} . J$. Power Sources 2010, 195, (2), 567-573.

(20) Huang, Y.-H.; Chou, H.-L.; Wang, F.-M.; Hwang, B.-J.; Liao, S.-C.; Huang, T.-N.; Su, C.-H.; Liu, H.-H., Synergy Between Experiment and Simulation in Describing the Electrochemical Performance of $\mathrm{Mg}$-Doped $\mathrm{LiNi}_{\mathrm{x}} \mathrm{Co}_{\mathrm{y}} \mathrm{Mn}_{\mathrm{z}} \mathrm{O}_{2}$ Cathode Material of Lithium Ion Battery. Int. J. Electrochem. Sci. 2013, 8, 8005-8018.

(21) Woo, S. W.; Myung, S. T.; Bang, H.; Kim, D. W.; Sun, Y. K., Improvement of Electrochemical and Thermal Properties of $\mathrm{Li}\left[\mathrm{Ni}_{0.8} \mathrm{Co}_{0.1} \mathrm{Mn}_{0.1}\right] \mathrm{O}_{2}$ Positive Electrode Materials by Multiple Metal (Al, Mg) Substitution. Electrochim. Acta 2009, 54, (15), 3851-3856.

(22) Liao, P.-Y.; Duh, J.-G.; Sheu, H.-S., Structural and Thermal Properties of $\mathrm{LiNi}_{0.6-\mathrm{x}} \mathrm{Mg}_{\mathrm{x}} \mathrm{Co}_{0.25} \mathrm{Mn}_{0.15} \mathrm{O}_{2}$ Cathode Materials. J. Power Sources 2008, 183, (2), 766-770.

(23) Xiang, M.; Tao, W.; Wu, J.; Wang, Y.; Liu, H., Synthesis and Electrochemical Performance of Spherical $\mathrm{LiNi}_{0.8} \mathrm{Co}_{0.15} \mathrm{Ti}_{0.05} \mathrm{O}_{2}$ Cathode Materials with High Tap Density. Ionics 2016, 22, (7), 10031009.

(24) Myung, S.-T.; Komaba, S.; Hosoya, K.; Hirosaki, N.; Miura, Y.; Kumagai, N., Synthesis of $\mathrm{LiNi}_{0.5} \mathrm{Mn}_{0.5-\mathrm{x}} \mathrm{Ti}_{\mathrm{x}} \mathrm{O}_{2}$ by an Emulsion Drying Method and Effect of $\mathrm{Ti}$ on Structure and Electrochemical Properties. Chem. Mater. 2005, 17, (9), 2427-2435.

(25) Sun, C. S.; Zhou, Z.; Xu, Z. G.; Wang, D. G.; Wei, J. P.; Bian, X. K.; Yan, J., Improved High-Rate Charge/Discharge Performances of $\mathrm{LiFePO}_{4} / \mathrm{C}$ via V-Doping. J. Power Sources 2009, 193, (2), 841-845.

(26) Li, H.; Chen, G.; Zhang, B.; Xu, J., Advanced Electrochemical Performance of $\mathrm{Li}\left[\mathrm{Ni}_{(1 / 3-x)} \mathrm{Fe}_{\mathrm{x}} \mathrm{Co}_{1 / 3} \mathrm{Mn}_{1 / 3}\right] \mathrm{O}_{2}$ as Cathode Materials for Lithium-Ion Battery. Solid State Commun. 2008, 146, (3 - 4), 115-120.
(27) Zhong, S.; Wang, Y.; Liu, J.; Wan, K.; LÜ, F., Synthesis and Electrochemical Properties of Ce-Doped $\mathrm{LiNi}_{1 / 3} \mathrm{Mn}_{1 / 3} \mathrm{Co}_{1 / 3} \mathrm{O}_{2}$ Cathode Material for Li-Ion Batteries. J. Rare Earths 2011, 29, (9), 891-895.

(28) Wang, M.; Chen, Y.; Wu, F.; Su, Y.; Chen, L.; Wang, D., Characterization of Yttrium Substituted $\mathrm{LiNi}_{0.33} \mathrm{Mn}_{0.33} \mathrm{Co}_{0.33} \mathrm{O}_{2}$ Cathode Material for Lithium Secondary Cells. Electrochim. Acta 2010, 55, (28), 8815-8820.

(29) Kang, S. H.; Amine, K., Layered $\mathrm{Li}_{(}\left(\mathrm{Li}_{0.2} \mathrm{Ni}_{0.15}+\right.$ $\left.{ }_{0.5 z} \mathrm{Co}_{0.10} \mathrm{Mn}_{0.55}-0.5 \mathrm{z}\right) \mathrm{O}_{2}{ }_{\mathrm{z}} \mathrm{F}_{\mathrm{z}}$ Cathode Materials for Li-Ion Secondary Batteries. J. Power Sources 2005, 146, (1 - 2), 654-657.

(30) Kageyama, M.; Li, D.; Kobayakawa, K.; Sato, Y.; Lee, Y.S., Structural and Electrochemical Properties of $\mathrm{LiNi}_{1 / 3} \mathrm{Mn}_{1 / 3} \mathrm{Co}_{1 / 3} \mathrm{O}_{2-\mathrm{x}} \mathrm{F}_{\mathrm{x}}$ Prepared by Solid State Reaction. J. Power Sources 2006, 157, (1), 494-500.

(31) He, Y.-S.; Pei, L.; Liao, X.-Z.; Ma, Z.-F., Synthesis of $\mathrm{LiNi}_{1 / 3} \mathrm{Co}_{1 / 3} \mathrm{Mn}_{1 / 3} \mathrm{O}_{2-} \mathrm{F}_{\mathrm{Z}}$ Cathode Material from Oxalate Precursors for Lithium Ion Battery. J. Fluorine Chem. 2007, 128, (2), 139-143.

(32) Zheng, J.; Wu, X.; Yang, Y., Improved Electrochemical Performance of $\mathrm{Li}\left[\mathrm{Li}_{0.2} \mathrm{Mn}_{0.54} \mathrm{Ni}_{0.13} \mathrm{Co}_{0.13}\right] \mathrm{O}_{2}$ Cathode Material by Fluorine Incorporation. Electrochim. Acta 2013, 105, 200-208.

(33) Liss, K.-D.; Hunter, B.; Hagen, M.; Noakes, T.; Kennedy, S., Echidna - the New High-Resolution Powder Diffractometer Being Built at OPAL. Physica B 2006, 385 - 386, Part 2, (0), 1010-1012.

(34) Toby, B. H.; Von Dreele, R. B., GSAS-II: the Genesis of a Modern Open-Source All Purpose Crystallography Software Package. J. Appl. Cryst. 2013, 46, (2), 544-549.

(35) Studer, A. J.; Hagen, M. E.; Noakes, T. J., Wombat: The High-Intensity Powder Diffractometer at the OPAL Reactor. Physica B 2006, 385 - 386, Part 2, (0), 1013-1015.

(36) Richard, D.; Ferrand, M.; Kearley, G. J., Analysis and Visualisation of Neutron-scattering Data. J. Neutron Res. 1996, 4, (14), 33-39.

(37) Pimenta, V.; Sathiya, M.; Batuk, D.; Abakumov, A. M.; Giaume, D.; Cassaignon, S.; Larcher, D.; Tarascon, J.-M., Synthesis of Li-rich NMC: A Comprehensive Study. Chem. Mater. 2017, DOI: 10.1021/acs.chemmater.7b03230.

(38) Karthikeyan, K.; Amaresh, S.; Lee, G. W.; Aravindan, V.; Kim, H.; Kang, K. S.; Kim, W. S.; Lee, Y. S., Electrochemical Performance of Cobalt Free, $\mathrm{Li}_{1.2}\left(\mathrm{Mn}_{0.32} \mathrm{Ni}_{0.32} \mathrm{Fe}_{0.16}\right) \mathrm{O}_{2}$ Cathodes for Lithium Batteries. Electrochim. Acta 2012, 68, (0), 246-253.

(39) Karthikeyan, K.; Amaresh, S.; Aravindan, V.; Kim, W. S.; Nam, K. W.; Yang, X. Q.; Lee, Y. S., Li( $\left(\mathrm{Mn}_{1 / 3} \mathrm{Ni}_{1 / 3} \mathrm{Fe}_{1 / 3}\right) \mathrm{O}_{2}-$ Polyaniline Hybrids as Cathode Active Material with Ultra-Fast Charge - Discharge Capability for Lithium Batteries. J. Power Sources 2013, 232, (0), 240-245.

(40) Shannon, R., Revised Effective Ionic Radii and Systematic Studies of Interatomic Distances in Halides and Chalcogenides. Acta Crystallogr. Sect. A 1976, 32, (5), 751-767.

(41) Ning, F.; Li, S.; Xu, B.; Ouyang, C., Strain Tuned Li Diffusion in $\mathrm{LiCoO}_{2}$ Material for Li Ion Batteries: A First Principles Study. Solid State Ionics 2014, 263, 46-48.

(42) Yabuuchi, N.; Kubota, K.; Dahbi, M.; Komaba, S., Research Development on Sodium-Ion Batteries. Chem. Rev. 2014, 114, (23), 11636-11682.

(43) Van der Ven, A.; Bhattacharya, J.; Belak, A. A., Understanding Li Diffusion in Li-Intercalation Compounds. Acc. Chem. Res. 2013, 46, (5), 1216-1225.

(44) Wan, W.; Zhang, Q.; Cui, Y.; Wang, E., First Principles Study of Lithium Insertion in Bulk Silicon. J. Phys. Condens. Matter 2010, 22, (41), 415501.

(45) Tian, H.; Seh, Z. W.; Yan, K.; Fu, Z.; Tang, P.; Lu, Y.; Zhang, R.; Legut, D.; Cui, Y.; Zhang, Q., Theoretical Investigation of 2D Layered Materials as Protective Films for Lithium and Sodium Metal Anodes. Adv. Energy Mater. 2017, 7, (13), 1602528.

(46) Whittingham, M. S., Lithium Batteries and Cathode Materials. Chem. Rev. 2004, 104, (10), 4271-4302. 
(47) Lee, E.; Park, J. S.; Wu, T.; Sun, C.-J.; Kim, H.; Stair, P. C.; Lu, J.; Zhou, D.; Johnson, C. S., Role of $\mathrm{Cr}^{3+} / \mathrm{Cr}^{6+}$ Redox in Chromium-Substituted $\mathrm{Li}_{2} \mathrm{MnO}_{3} \cdot \mathrm{LiNi}_{1 / 2} \mathrm{Mn}_{1 / 2} \mathrm{O}_{2}$ Layered Composite Cathodes: Electrochemistry and Voltage Fade. J. Mater. Chem. 2015, 3, (18), 9915-9924.

(48) Lu, Z.; Dahn, J. R., Structure and Electrochemistry of Layered $\mathrm{Li}_{[}\left[\mathrm{Cr}_{\mathrm{x}} \mathrm{Li}_{(1 / 3-\mathrm{x} / 3)} \mathrm{Mn}_{(2 / 3-2 \mathrm{x} / 3)}\right] \mathrm{O}_{2}$. J. Electrochem. Soc. 2002, 149, (11), A1454-A1459.

(49) Karan, N. K.; Abraham, D. P.; Balasubramanian, M.; Furczon, M. M.; Thomas, R.; Katiyar, R. S., Morphology, Structure, and Electrochemistry of Solution-Derived $\mathrm{LiMn}_{0.5-\mathrm{x}} \mathrm{Cr}_{2 \mathrm{x}} \mathrm{Ni}_{0.5-\mathrm{x}} \mathrm{O}_{2}$ for Lithium-Ion Cells. J. Electrochem. Soc. 2009, 156, (7), A553-A562.

(50) Balasubramanian, M.; McBreen, J.; Davidson, I. J.; Whitfield, P. S.; Kargina , I., In Situ X-Ray Absorption Study of a Layered Manganese-Chromium Oxide-Based Cathode Material. $J$. Electrochem. Soc. 2002, 149, (2), A176-A184.

(51) Kodama, R.; Terada, Y.; Nakai, I.; Komaba, S.; Kumagai, N., Electrochemical and In Situ XAFS-XRD Investigation of $\mathrm{Nb}_{2} \mathrm{O}_{5}$ for Rechargeable Lithium Batteries. J. Electrochem. Soc. 2006, 153, (3), A583-A588.
(52) Wang, F.; Xiao, S.; Li, M.; Wang, X.; Zhu, Y.; Wu, Y. Shirakawa, A.; Peng, J., A Nanocomposite of $\mathrm{Li}_{2} \mathrm{MnO}_{3}$ Coated by $\mathrm{FePO}_{4}$ as Cathode Material for Lithium Ion Batteries. J. Power Sources 2015, 287, 416-421.

(53) Wang, F.; Chang, Z.; Wang, X.; Wang, Y.; Chen, B.; Zhu, Y.; Wu, Y., Composites of Porous $\mathrm{Co}_{3} \mathrm{O}_{4}$ Grown on $\mathrm{Li}_{2} \mathrm{MnO}_{3}$ Microspheres as Cathode Materials for Lithium Ion Batteries. $J$. Mater. Chem. A 2015, 3, (9), 4840-4845.

(54) Kobayashi, G.; Irii, Y.; Matsumoto, F.; Ito, A.; Ohsawa, Y.; Yamamoto, S.; Cui, Y.; Son, J.-Y.; Sato, Y., Improving Cycling Performance of Li-Rich Layered Cathode Materials through Combination of $\mathrm{Al}_{2} \mathrm{O}_{3}$-Based Surface Modification and Stepwise Precycling. J. Power Sources 2016, 303, 250-256.

(55) Ye, D. L.; Zeng, G.; Nogita, K.; Ozawa, K.; Hankel, M.; Searles, D. J.; Wang, L. Z., Understanding the Origin of $\mathrm{Li}_{2} \mathrm{MnO}_{3}$ Activation in Li-Rich Cathode Materials for Lithium-Ion Batteries. Adv. Funct. Mater. 2015, 25, (48), 7488-7496. 
Table of contents

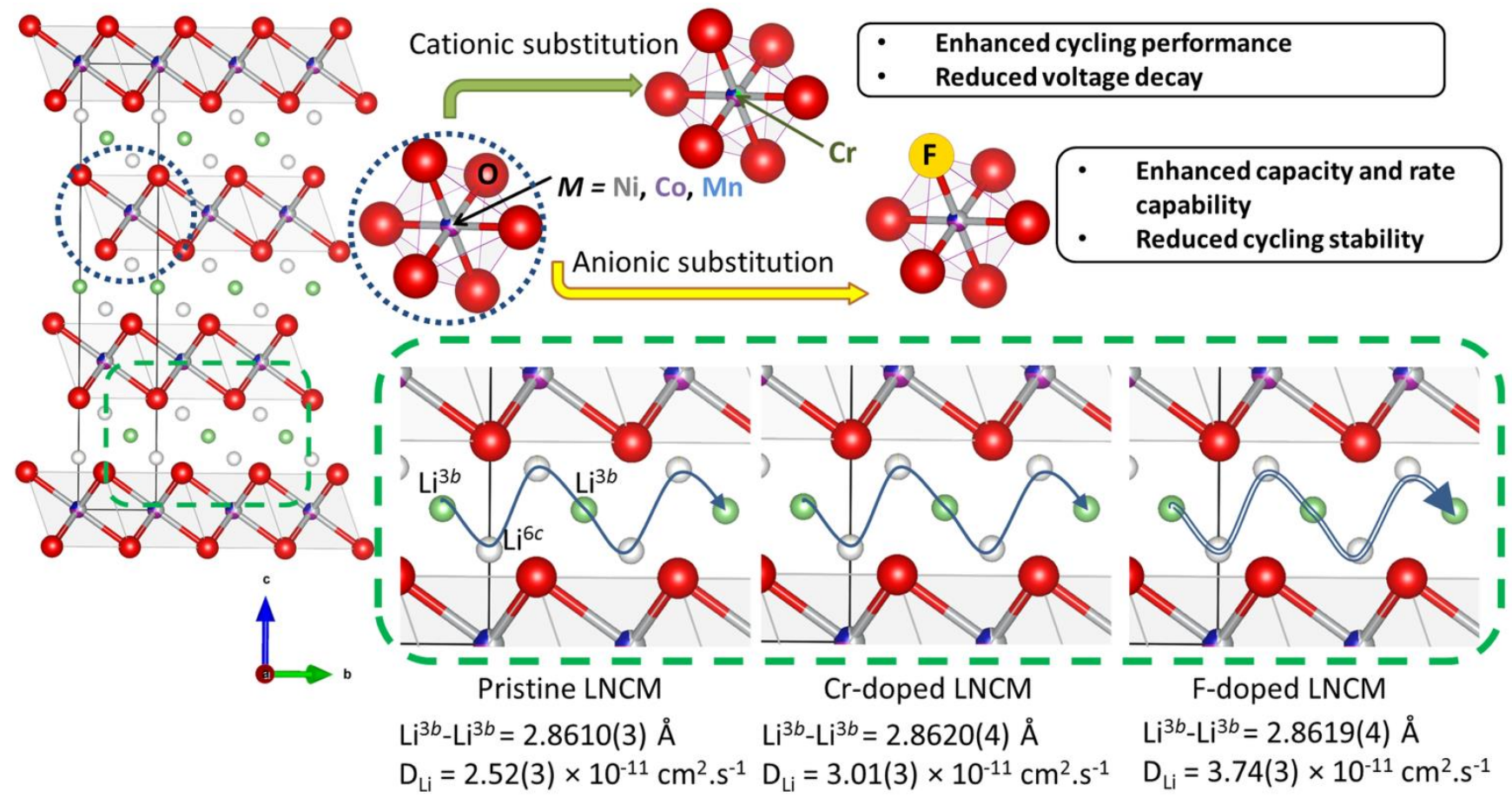

